\title{
Unbiased identification of novel transcription factors in striatal compartmentation and striosome maturation
}

\begin{abstract}
Maria-Daniela Cirnaru' ${ }^{1}$, Sicheng Song ${ }^{2}$, Kizito-Tshitoko Tshilenge ${ }^{3}$, Chuhyon Corwin ${ }^{1}$, Justyna Mleczko ${ }^{1}$, Carlos Galicia Aguirre ${ }^{3}$, Houda Benlhabib ${ }^{2}$, Jaroslav Bendl4,5,6, Pasha Apontes 4,5,6, John Fullard 4,5,6, Jordi Creus-Muncunill', Azadeh Reyahi ${ }^{7}$, Ali M Nik7, Peter Carlsson7, Panos Roussos ${ }^{4,5,6,8}$, Sean D Mooney ${ }^{2}$, Lisa M Ellerby ${ }^{3}$, Michelle E Ehrlich ${ }^{1 *}$
\end{abstract}

${ }^{1}$ Department of Neurology, Icahn School of Medicine at Mount Sinai, New York, United States; ${ }^{2}$ Department of Biomedical Informatics and Medical Education, University of Washington, Seattle, United States; ${ }^{3}$ Buck Institute for Research on Aging, Novato, United States; ${ }^{4}$ Pamela Sklar Division of Psychiatric Genomics, Icahn School of Medicine at Mount Sinai, New York, United States; ${ }^{5}$ Institute for Genomics and Multiscale Biology, Department of Genetics and Genomic Sciences, Icahn School of Medicine at Mount Sinai, New York, United States; ${ }^{6}$ Department of Psychiatry, Icahn School of Medicine at Mount Sinai, New York, United States; ${ }^{7}$ Department of Chemistry and Molecular Biology, University of Gothenburg, Gothenburg, Sweden; ${ }^{8}$ Mental Illness Research, Education, and Clinical Center (VISN 2 South), Bronx, United States
*For correspondence:

michelle.ehrlich@mssm.edu

Competing interests: The authors declare that no competing interests exist.

Funding: See page 27

Preprinted: 22 May 2020 Received: 21 December 2020 Accepted: 20 August 2021 Published: 05 October 2021

Reviewing editor: Sonia Sen, Tata Institute for Genetics and Society, India

(c) Copyright Cirnaru et al. This article is distributed under the terms of the Creative Commons Attribution License, which permits unrestricted use and redistribution provided that the original author and source are credited.
Abstract Many diseases are linked to dysregulation of the striatum. Striatal function depends on neuronal compartmentation into striosomes and matrix. Striatal projection neurons are GABAergic medium spiny neurons (MSNs), subtyped by selective expression of receptors, neuropeptides, and other gene families. Neurogenesis of the striosome and matrix occurs in separate waves, but the factors regulating compartmentation and neuronal differentiation are largely unidentified. We performed RNA- and ATAC-seq on sorted striosome and matrix cells at postnatal day 3, using the Nr4a1-EGFP striosome reporter mouse. Focusing on the striosome, we validated the localization and/or role of Irx1, Foxf2, Olig2, and Stat1/2 in the developing striosome and the in vivo enhancer function of a striosome-specific open chromatin region $4.4 \mathrm{~Kb}$ downstream of Olig2. These data provide novel tools to dissect and manipulate the networks regulating MSN compartmentation and differentiation, including in human iPSC-derived striatal neurons for disease modeling and drug discovery.

\section{Introduction}

Dysregulation of the striatum is linked to multiple neuropsychiatric diseases, including Huntington's (HD), Parkinson's, X-linked dystonia-parkinsonism, addiction, autism, and schizophrenia. The dorsal striatum comprises the caudate and putamen in humans but consists of a single nucleus in the mouse. This nucleus is a key component of cortical and subcortical circuits regulating movement, reward, and aspects of cognition, including speech and language. 85 to $95 \%$ of striatal neurons are medium spiny (MSNs), the striatal projection neuron. They are morphologically homogeneous, but 
phenotypically heterogeneous, and adult subtypes are distinguished by unique transcriptomes (Anderson et al., 2020; Gokce et al., 2016; Ho et alı, 2018; Märtin et al., 2019; MuñozManchado et al., 2018; Ortiz et al., 2020; Stanley et al., 2020; Zeisel et al., 2018). MSNs are equally distributed between direct neurons (dMSNs), which express the dopamine D1 receptor (D1R) and project directly to the substantia nigra (SN) or to the internal segment of the globus pallidus, and indirect neurons (iMSNs), which express the dopamine D2 (D2R) and adenosine 2A receptors (A2aR) and project to the external segment of the globus pallidus or to the subthalamic nucleus (Keeler et al., 2014).

The striatum is comprised of two main compartments named striosomes (patch) and matrix. Striosomes occupy $10-15 \%$ of the volume and are dispersed in a continuum throughout the $80-85 \%$ occupied by the matrix. Importantly, an imbalance between striatal compartments likely contributes to movement disorders (Cazorla et al., 2015; Crittenden and Graybiel, 2011; Keeler et al., 2014), and compartmentation also appears to be required for non-motor functions, for example, speech and language and discrimination learning (Campbell et alo, 2009; Deriziotis and Fisher, 2017; Feuk et al., 2006; Konopka et alo, 2009; Lai et al., 2001; MacDermot et al., 2005). In X-linked dystonia-parkinsonism, degeneration is initiated in the striosomes (Beste et al., 2018; Goto et alo, 2005). Compartmentation is altered in autism (Kuo and Liu, 2020), and HD features early, preferential loss of striosome neurons (Victor et al., 2014). Moreover, dopaminergic signaling has opposing effects on D1R activation in a compartment-specific manner, which is important for task dependent behaviors (Prager et al., 2020). The distinction between the striosome and matrix in adults is based on differences in gene expression, the origins of afferents from cortical regions (e.g. sensorimotor, limbic, and associative), and to some extent, by the destination of their efferents (Brimblecombe and Cragg, 2017; Crittenden and Graybiel, 2011; Fujiyama et al., 2019). They both contain direct and indirect neurons, but the striosome dMSN content regionally varies (Cirnaru et al., 2019; Miyamoto et al., 2018). Currently, no robust differentiation protocol is available for the generation of striosome cells for in vitro studies and replacement therapies (Arber et al., 2015; Golas, 2018; Kemp et al., 2016; Richner et al., 2015; Telezhkin et alı, 2016; Victor et al., 2014), and the molecular mechanisms governing compartmentation are incompletely defined.

Striosome and matrix compartments differ in their developmental timelines, as there are two waves of striatal neurogenesis (Matsushima and Graybiel, 2020). Striosome MSNs complete mitosis by embryonic day 13 (E13) and project toward substantia nigra pars compacta by E18 (Fishell and van der Kooy, 1987; Fishell and van der Kooy, 1989). Matrix MSNs are born in the second wave and are postmitotic by E18-E20 and do not project toward substantia nigra until the first postnatal week (Fishell and van der Kooy, 1987; Fishell and van der Kooy, 1989). This period is essential for the specification of striatal compartmentation, and most of the markers that distinguish striosome from matrix do not reach their final adult distribution until at least the second postnatal week. For example, dopamine- and cAMP-regulated neuronal phosphoprotein (DARPP-32), encoded by Ppp1r1b, is expressed in $95 \%$ of the MSNs at maturity and is the most commonly used pan-MSN marker (Arber et al., 2015; Chandwani et al., 2013; Fjodorova et al., 2019; Fullard et al., 2018; Ivkovic and Ehrlich, 1999), but it is unequivocally a marker of striosomes during the first postnatal week (Arlotta et al., 2008). Mu opiate receptor (MOR) protein, encoded by the Oprm1 gene, marks the striosome neurons at all ages but conversely, calbindin, encoded by Calb1, is the most widely used matrix marker in studies of adult striatum, but at PND3, is expressed in nascent striosomes (Anderson et al., 1997; Arlotta et al., 2008; Crittenden and Graybiel, 2011; Liu and Graybiel, 1992; Passante et al., 2008; Snyder-Keller et al., 2008). A recent study analyzing P9 striosome and matrix confirms that maturation is not yet complete, based on comparisons to distribution of adult markers (Anderson et alo, 2020). The developmental cascade for the two compartments is shown schematically in the upper panel of Figure 1.

Multiple transcription factors (TFs) are required for induction and differentiation into MSN subtypes (Arlotta et al., 2008; Fjodorova et al., 2019; Golas, 2018; Ivkovic and Ehrlich, 1999; Long et al., 2009; Marin et alı, 2000; Martín-lbáñez et alı, 2012; Martín-lbáñez et al., 2017; Precious et al., 2016; Victor et al., 2014; Wang et al., 2011b; Zhang et al., 2016), and some are useful for direct conversion of human fibroblasts into MSNs (Hedreen and Folstein, 1995; Lawhorn et alo, 2008). Importantly, a widely used protocol yielded only a matrix phenotype (Victor et al., 2014), and several others yielded largely calbindin-positive neurons, with no mention 


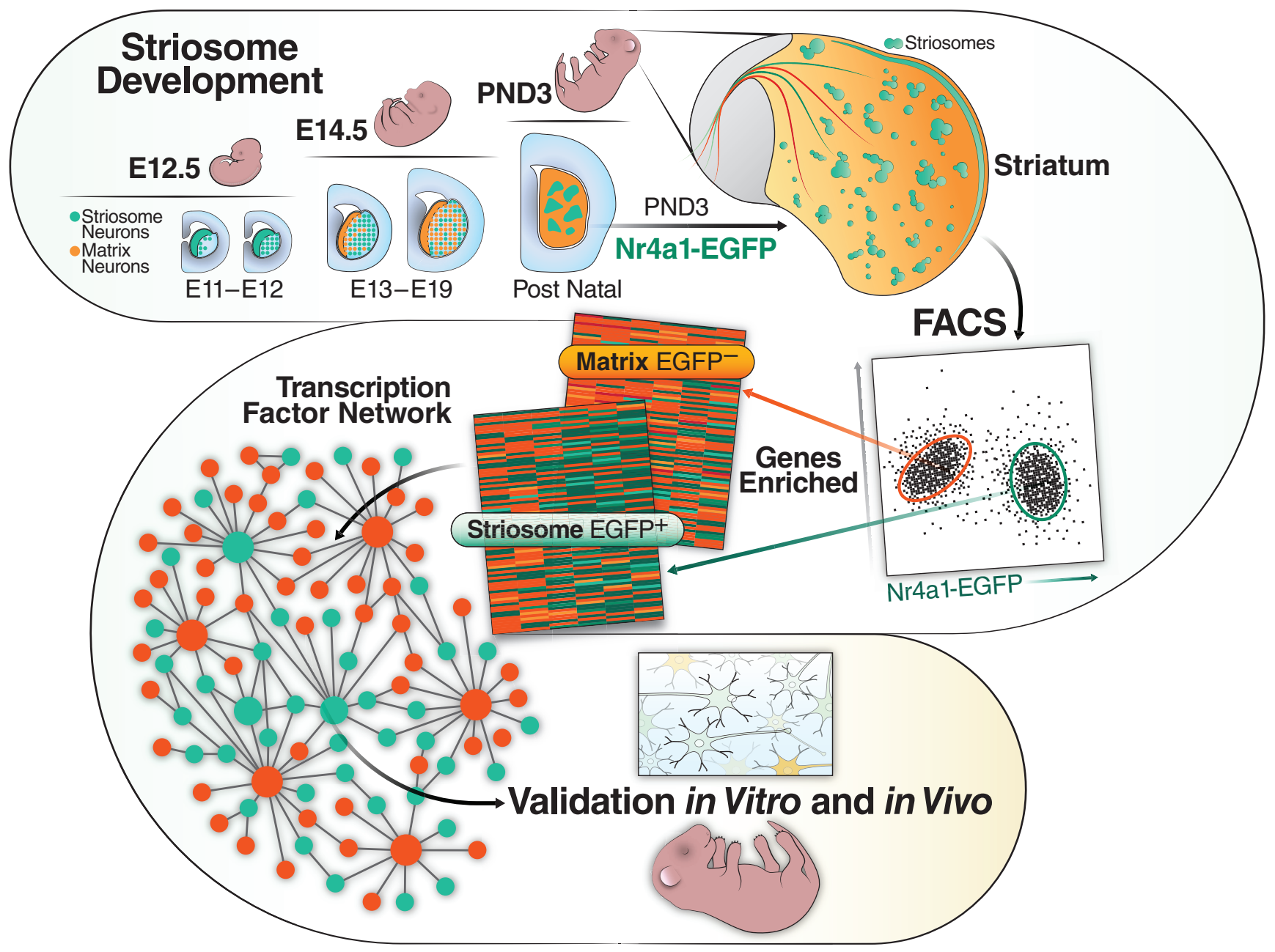

Figure 1. Schematic of the developmental cascade for the striosome and matrix compartments and our experimental approach. Upper panel shows the cascade of the two compartments in the developing mouse. Lower panels show our experimental approach. We FACs sorted EGFP ${ }^{+}$cells from Nr4a1 EGFP mice at PND3, performed RNAseq, identified top transcription factors in the striosome, validated them in vivo (mice) and in vitro (primary mouse cultures and human iPSCs).

of a striosome phenotype (Adil et al., 2018; Arber et al., 2015; Golas, 2018; Kemp et al., 2016; Telezhkin et al., 2016). Only a handful of TFs and signaling systems contributing to striosome/ matrix compartmentation have been identified, including Ikaros-1, retinoids, Foxp1, and Nr4a1 (Cirnaru et al., 2019; Evans et al., 2012; Kuo and Liu, 2017; Lai et al., 2001; MartínIbáñez et al., 2012; Martín-lbáñez et al., 2017; Rataj-Baniowska et al., 2015), the absence of which in some cases reduces the area occupied by striosomes but does not prevent the formation of the basic architecture.

We used unbiased transcriptomic and epigenetic assays, RNA-seq and ATAC-seq, to identify TFs and open chromatin regions (OCRs) associated with striosome maturation on postnatal day 3, specifically after they are first formed but not yet mature (Figure 1). Genes expressed at this point may also include terminal differentiation effectors as defined by Hobert, 2016, which initiate and maintain the adult identity of neurons. We used the GENSAT Nr4a1-EGFP mouse, in which reporter expression is directed to striosomes throughout the life of the mouse (Cirnaru et al., 2019; Davis and Puhl, 2011), including as specifically described on PND3. As we did not know which of the adult striosome and matrix markers were already expressed in their respective, final compartments on PND3 which could be used to assign neuronal identity, we opted to perform bulk RNA- 
seq on cells sorted by fluorescence-activated cell sorting (FACS) rather than single cells, also possibly increasing the capture of low expression genes (Figure 1). We developed complementary databases of the EGFP-negative cells, enriched in developing matrix neurons. We validated the localization and/or role of Irx1, Foxf2, Olig2, and Stat1/2 in the developing mouse striosome and the in vivo enhancer function of a striosome-specific open chromatin region $4.4 \mathrm{~Kb}$ downstream of the 3' end of the Olig2 gene. We also show that Foxf2, Olig2, and Stat1/2 drive the expression of MSN maturation in human NSCs derived from HD-iPSCs. The identified TFs and OCRs greatly add to the understanding of MSN development and allow for the generation of additional MSN subtypes for disease modeling.

\section{Results}

\section{Transcriptional analysis of Nr4a1-EGFP mice identify striatal compartment-specific TFs in vivo}

The TF Nr4a1 is a member of the Nur family of steroid/thyroid-like receptors (Giguère, 1999) and is expressed in the mouse striosome MSNs as early as embryonic day (E) 14.5 (Davis and Puhl, 2011). GENSAT mice express the EGFP reporter from a transgenic Nr4a1 bacterial artificial chromosome (Nr4a1-EGFP), and at PND3, EGFP co-localizes with Oprm1, D1R, and tyrosine hydroxylase islands. We confirmed co-localization with Oprm1/MOR and further demonstrated that EGFP co-localizes to a large extent with DARPP-32 (Figure 2-figure supplement 1A). A list of striosome and matrix markers used in this report is presented in Table 1. Notably, the overlap with several of these markers is not $100 \%$ but does include the subcallosal streak. Nr4a1-EGFP-positive and -negative cell populations, representing enriched striosome and matrix MSN populations, respectively (Figure 2B), were isolated by FACS using spontaneous fluorescence. Visual inspection confirmed separation of the two populations (Figure 2C). RT-qPCR analysis of the sorted populations indicated significant enrichment of PND3 striosome markers Ppp1r1b and Oprm1, Nr4a1 and GFP in the EGFP+ population (Figure 2-figure supplement 1B). Map2, associated with more mature neurons, was enriched, whereas glial fibrillary acidic protein (Gfap) mRNA was relatively lower in the EGFP+ sample, indicating neuronal enrichment in this fraction. Tuj1, associated with immature neurons (Menezes and Luskin, 1994) was enriched in the EGFP- population (Figure 2-figure supplement 1B). We concluded that the sorting captured a large subset of PND3 striosome neurons. The extent of inclusion of other cell types, including exopatch neurons, is discussed below.

Next, we carried out RNA-seq, transcriptomic analysis on both the EGFP+ and EGFP-cells (Figure 2-source data 1). A total of 9124 genes were differentially expressed between the two groups, with 4714 enriched in the EGFP+ cells (positive log2FC) and 4410 enriched in the EGFP- cells (negative log2FC) $(p<0.01$, Figure 2-source data 1), but this entire list includes many genes with small differences between compartments. Twenty-three differentially expressed genes were selected with

Table 1. List of striosome and matrix markers.

\begin{tabular}{llll} 
Gene symbol & Gene name & PND3 & Adult \\
\hline Calb1 & Calbindin & Striosome & Matrix \\
\hline EfnA5 & Ephrin A5 & Striosome & \\
\hline EphA4 & Eph Receptor A4 & Matrix & Matrix \\
\hline EphA7 & Eph Receptor A7 & Striosome & \\
\hline FoxP1 & Forkhead Box P1 & Striosome & pan-MSN \\
\hline FoxP2 & Forkhead Box P2 & Striosome & Striosome \\
\hline Nr4a1 & Nuclear Receptor Subfamily 4 Group Member 1 & Striosome & Striosome \\
\hline Oprm1 & Mu opioid receptor & Striosome & Striosome \\
\hline Ppp1r1b & Protein phosphatase 1 regulatory subunit 1B & Striosome & pan-MSN \\
\hline Rasgrp1 & CalDAG GEFIl & Striosome & Striosome \\
\hline Rasgrp2 & CalDAG GEFI & Matrix & Matrix \\
\hline
\end{tabular}


A

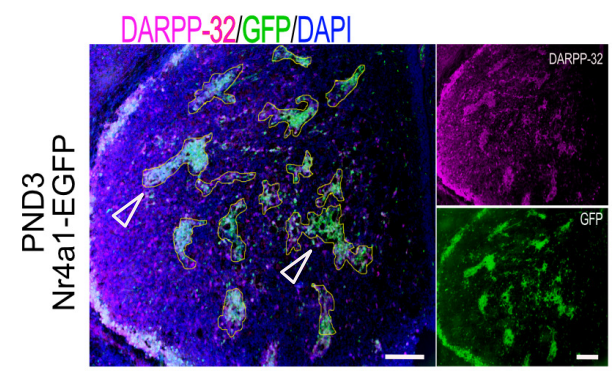

E

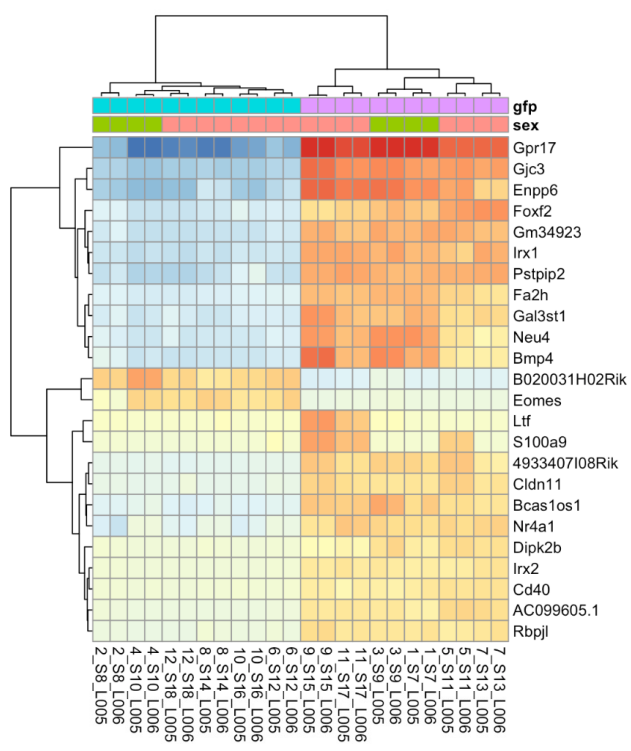

G

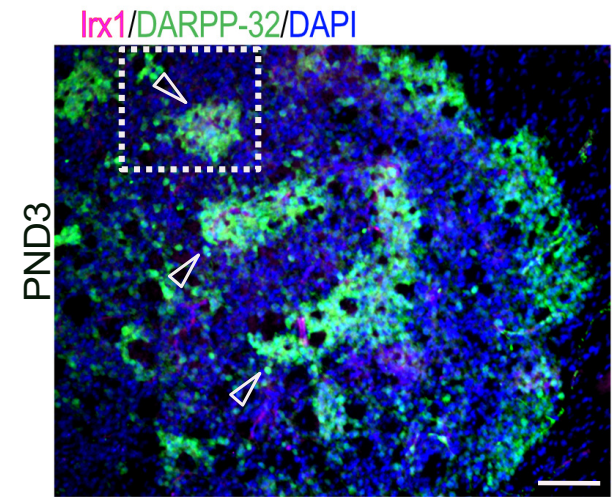

B
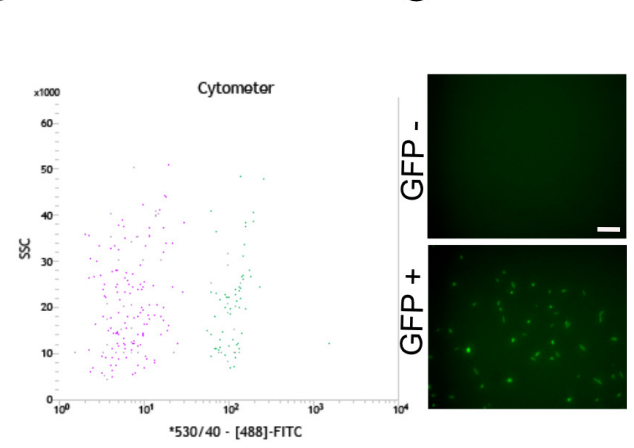

$\mathrm{F}$

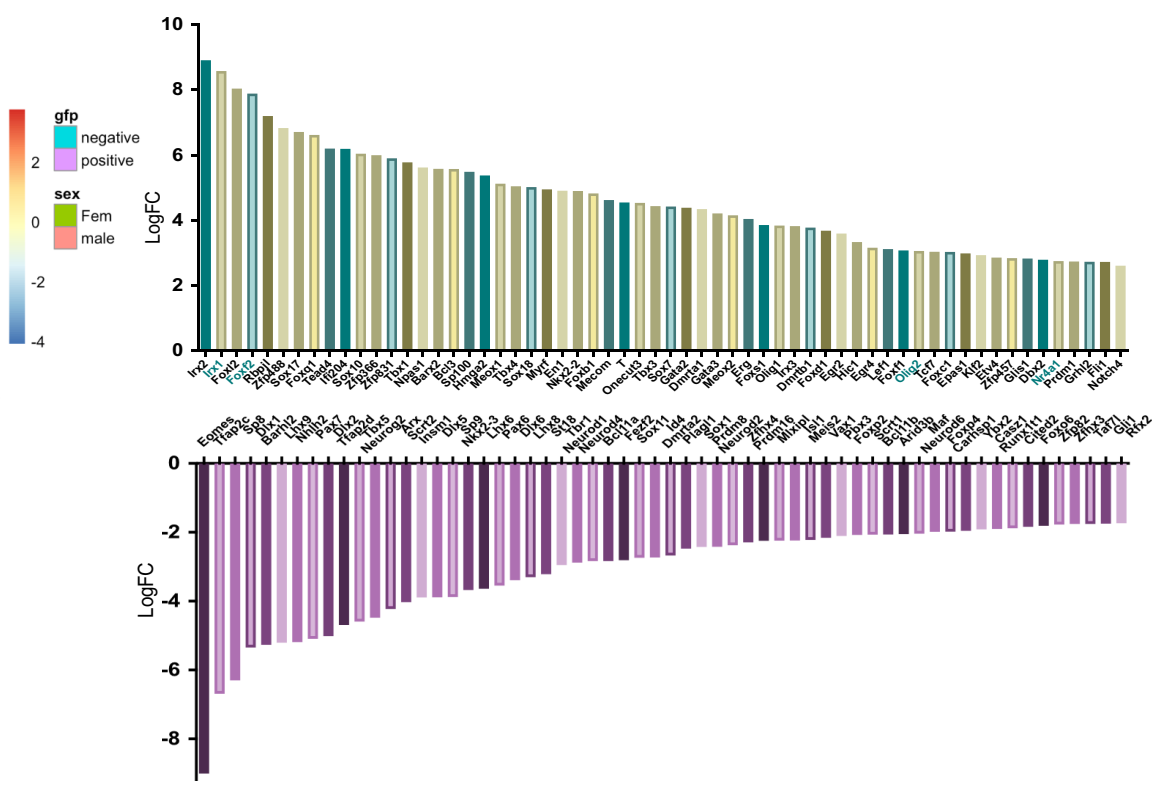

D

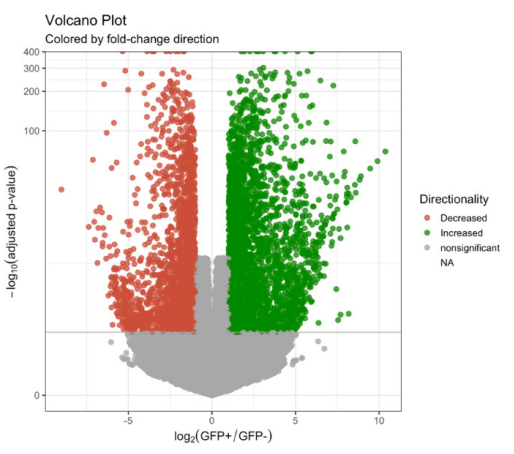

D
C 
Figure 2 continued

highlighted. Red indicates genes that were relatively decreased in expression in EGFP ${ }^{+}$population (i.e. enriched in the EGFP ${ }^{-}$population), green indicates genes that were relatively enriched in expression in the EGFP ${ }^{+}$population, and gray indicates those genes that were equally distributed in the two populations. (E) Heatmap of relative normalized counts across samples of genes with an absolute log2 fold-change $>7$, and mean normalized counts $>40$. (F) Representation of the 60 TFs most enriched in either population, according to their log2 fold change in the EGFP ${ }^{+}$population (upper panel) and in the EGFP- population (lower panel), without regard to mean normalized counts. (G) Representative low- and high-power micrographs of Irx1 (magenta), DARPP-32 (green) and DAPI (blue) immunolabeling on 16- $\mu$ m-thick coronal sections from wild-type PND3 showing the localization of Irx1 within a subset of the DARPP-32 immunopositive striosomes (arrowheads left panel), with double label of a subset of striosome neurons indicated by the arrowheads (right panel). Scale bars $=100 \mu \mathrm{m}$ and $20 \mu \mathrm{m}$, respectively.

The online version of this article includes the following source data and figure supplement(s) for figure 2:

Source data 1. RNA sequencing analysis of the transcripomes of striosome and matrix cells from the PND3 striatum striosome and matrix compartments expressed as a ratio of Nr4a1-EGFP+/Nr4a1-EGFP- following FACS sorting.

Figure supplement 1. Validation of Nr4a1-EGFP striosome localization and characterization of EGFP+ and EGFP-cell population after FACS sorting.

an arbitrary threshold of log2FC greater than seven and mean normalized counts greater than 40, which along with $\mathrm{Nr} 4 \mathrm{a} 1$, are shown in the heatmap (Figure 2E). The heatmap includes Irx1, Irx2 and Foxf2 as top candidates for a role in defining the striosome, based on their relative distribution.

The Nr4a1 log2FC indicates highly significant $[\mathrm{p}(\mathrm{adj})=1.47 \mathrm{E}-113]$ enrichment in the striosome compartment but suggests by its relatively lower value, +2.75 , that the EGFP expression directed by the BAC transgene may not perfectly replicate endogenous Nr4a1 expression.

To further highlight compartmentalized differentially expressed TFs, we used the mouse TF database (Figure 2-source data 1). The top 60 TFs enriched in each population according to their log2FC [i.e., EGFP+ population relative to the EGFP- (upper panel), and in the EGFP-population (lower panel), without regard to mean normalized counts] are shown in Figure 2F. TFs enriched in the $\mathrm{EGFP}^{+}$group include Foxf2 as noted above and Olig2, which are enriched seven- and threefold over their expression levels in the matrix, respectively. Gene sets that are enriched in the EGFPcompartment include numerous known and novel genes that may have a role in the overall specification of the MSN and particularly matrix MSNs (Arlotta et alı, 2008; Fjodorova et al., 2019; Golas, 2018; Ivkovic and Ehrlich, 1999; Long et al., 2009; Marin et al., 2000; MartínIbáñez et al., 2012; Martín-lbáñez et alı, 2017; Precious et al., 2016; Victor et al., 2014; Wang et al., 2011b; Zhang et al., 2016). Known striatal TFs include FoxP1, Dlx1,2,6, Gsx2, Mash1, $N k x 2.1, L h x 6$, and $L h x 7$. The latter three are associated with interneurons. The full list of TFs that define the striosome and matrix at this age are summarized in Figure 2-source data 1. We identified 621 differentially expressed TFs. Among these, 259 were enriched in the EGFP+ cells, and 362 were enriched in the EGFP- cells.

The ongoing maturation of the two compartments was further highlighted by the localization of other mRNAs recently associated with striosome, matrix, and exopatch (Ortiz et al., 2020; Saunders et al., 2018; Smith et al., 2016). The fact that some of these are not yet compartmentalized and/or not present in the data base confirms that both neuronal maturation and compartmentation are incomplete on PND3. Thus, adult and/or PND9 striosome markers Sema5b, Kremen1, Tac1, Spon1, Sorcs1, Cdh18, Coh10, and Asic4 are all enriched in the EGFP+ compartment, but Mfge8, Sepw1, and LyPd1 are evenly distributed between EGFP+ and EGFP- cells, and Pde1c and Tshz1 mRNAs are enriched in the EGFP- compartment, as is Foxp2. Of the exopatch markers Casz1, Otof, Ntng1, and Asic2, only the latter is enriched in the EGFP+ compartment, so it is unknown whether we are capturing exopatch neurons.

As the Irx $1 / 2$ genes were among the most enriched TFs in the striosomes and have not been associated with the striatum, we carried out immunostaining of Irx1 to validate the predicted protein distribution. Irx1 co-localizes with a subset of DARPP-32 immunopositive striosomes in wild-type PND3 mice, validating its predicted striosome enrichment (Figure 2G).

\section{Analysis of striosome-enriched transcription networks define Foxf2 and Olig2 as key differentiation factors}

To identify potential master regulators driving the transcription program of the striosome, we conducted TF and co-expressor enrichment analysis with Enrichr (Chen et al., 2013; Kuleshov et al., 2016). We input the list of either differentially expressed genes or differentially expressed 
transcription factors to obtain the upstream regulators and co-expressors for both gene sets $(p<0.05)$. The intersect of the enrichment results and the differentially expressed TFs were further used as input to generate striosome- and matrix-specific TF co-expression networks, using GeneMANIA (Warde-Farley et al., 2010) as a prediction tool (Figure 3A,B). This allowed the generation of network reconstruction and expansion for striosome and matrix differentially expressed TFs. From the network analysis, we observed that striosome-enriched Nr4a1, Irx1, Olig2, and Foxf2 interacted with a large number of TFs (Figure 3A), indicating that these four TFs are likely critical in the development of striosomes and the MSNs located therein, as we already showed for Nr4a1 (Cirnaru et al., 2019). Since Foxf2 and Olig2 are potential novel regulators of the striosome (Figure 3E,F), we asked whether or not their targets were co-regulated in this compartment. We found that, in the striosome, the transcriptional targets of Foxf2 and Olig2 are indeed upregulated, i.e., enriched, relative to the matrix, and predicted to be coordinately regulated (Figure $3 C, D$ ). The TF network analysis of the matrix (Figure $3 B$ ) indicates $D / x 1$ and $D / x 2$ are hub TFs. Potentially newly defined hub TFs in the matrix include Pax7, Barhl2, Lhx9, Nhlh2, Eomes, and Sp8 (Figure 3B), the latter already associated with development of iMSNs (Xu et al., 2018).

In addition to defining the transcriptional network for the striosome and matrix, we analyzed the differentially expressed genes for overrepresented biological annotations or pathways, including GO term and KEGG pathway enrichment analysis (The Gene Ontology Consortium, 2017; Figure 2source data 1). Striosome enriched genes were associated with general development, for example, integrins, angiogenesis or cell motility, and nodes include 'regulation of pre-synapse organization'. Matrix-enriched genes were associated with neural system development and neurotransmission (Figure 3E). Both Nr4a1 and Foxf2 are associated with angiogenesis and/or establishment of the blood brain barrier (Reyahi et alı, 2015; Zeng et al., 2006), which play synergistic roles with brain and neuronal development (Haddad-Tóvolli et al., 2017). Calcium regulation was associated with both gene sets. We also conducted a similar analysis with the differentially expressed TFs. For visualization and interaction network and GO enrichment analysis, TFs in the EGFP+ compartment are highly involved in embryonic organ development (Sox17, Gata3, Cebp, Nr4a3, Foxf1, Foxf2), cellfate commitment (Sox2, Cebp, Stat3, Olig1 and Olig2) and transcription activation, including RNA polymerase II binding factors and enhancer binding (Id1, Klf4, Tbx3, Erg2, Stat3), indicating an active, open chromatin structure (Figure 2-source data 1).

\section{ATAC-seq analysis defines compartment-specific OCRs in the striatum}

To map chromatin accessibility of striosome and matrix cells, we used FACS, followed by preparation of eight ATAC-seq libraries from 12 animals pooled in four independent samples for the EGFP+ and EGFP- populations. Overall, we obtained 322 million (average of 40.3 million) uniquely mapped reads after removing duplicates and those aligning to the mitochondrial genome (Figure 4-source data 1). To quantitatively analyze differences between striosome and matrix cells, we generated a consensus set of 69,220 OCRs by taking the union of peaks called in the individual cells (Materials and methods). We next quantified the number of reads that overlapped each OCR. Uniform Manifold Approximation and Projection for Dimension Reduction (UMAP)-based clustering using the normalized read counts clearly separated striosome from matrix samples (Figure 4A). Comparison of striosome and matrix peaks resulted in $44 \%$ of OCRs that were significant after multiple testing corrections $(30,799$ differentially modified OCRs at FDR $\leq 0.05)$ (Figure 4-source data 2). Among these, 16,963 were striosome, and 13,836 were matrix.

We examined the location of OCRs with respect to the distance from transcription start sites (TSS) and genic annotations. As expected, OCRs are in the vicinity of TSSs (Figure 4B) but are also enriched for non-promoter regulatory elements, suggesting a more important role for long-range regulation of gene expression in developing striosome and matrix. We tested the concordance of striosome and matrix-specific genes and OCRs, based on the RNA-seq and ATAC- seq analyses, respectively, and found a moderately high correlation (Pearson's $\mathrm{R}=0.34$; $\mathrm{p}$-value $<2.2 \times 10-16$ ) (Figure 4C). To determine if the ATAC-seq identified regulatory regions relevant to Nr4a1-EGFP enriched expression in the striosome, we compared the tracks from PND3 EGFP+ and EGFP- populations for the presence of putative Nr4a1 cis-regulatory elements (Figure 4D). Indeed, a number of distinct OCRs within the Nr4a1 gene were associated with the EGFP+ cells. Next, we used HOMER (Heinz et alo, 2010) to identify which TF binding motifs were selectively enriched in the OCRs of EGFP+ and EGFP- populations. De novo motif enrichment analysis of the EGFP+ OCRs showed 


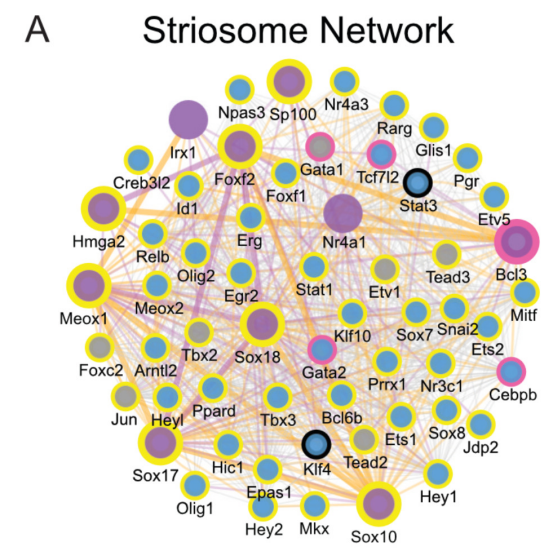

C

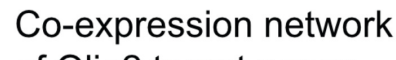
of Olig2 target genes

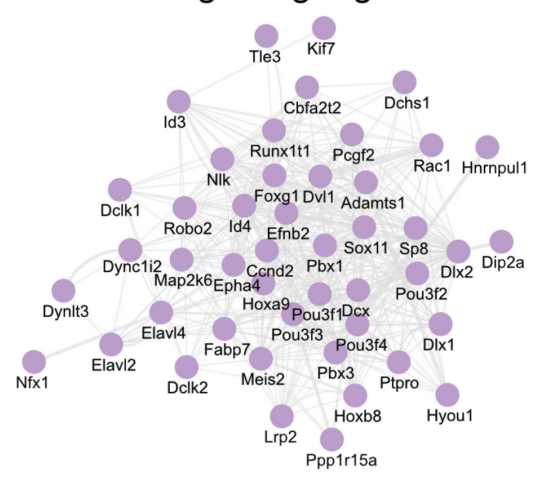

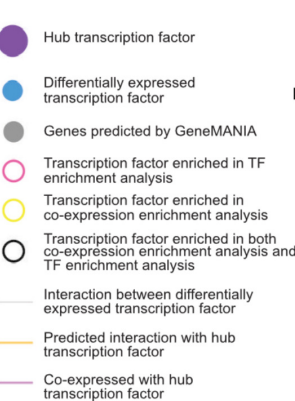

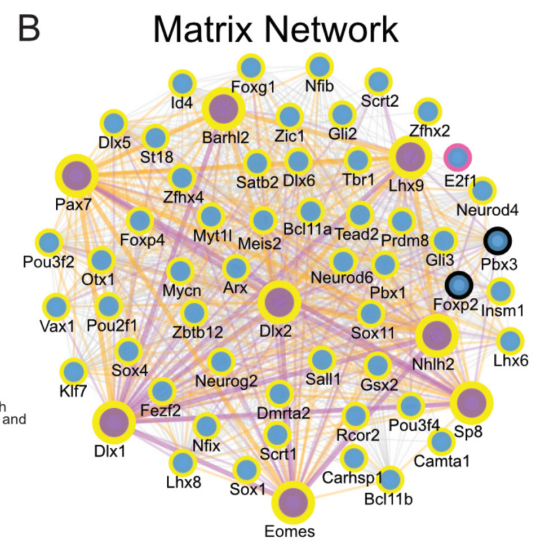

\section{Co-expression network of Foxf2 target genes}

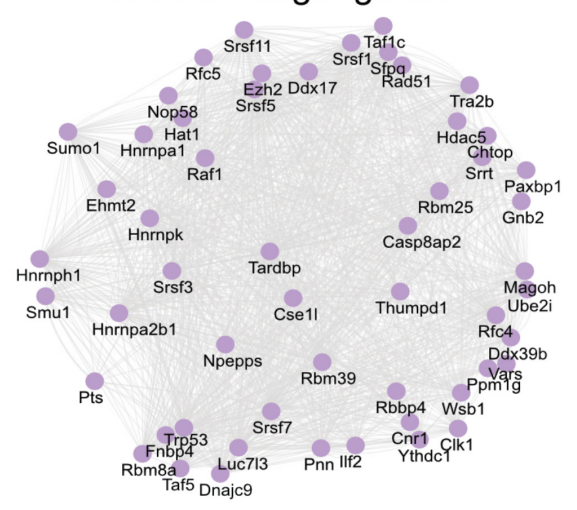

E

\section{Pathway and network enrichment (GO-BP)}

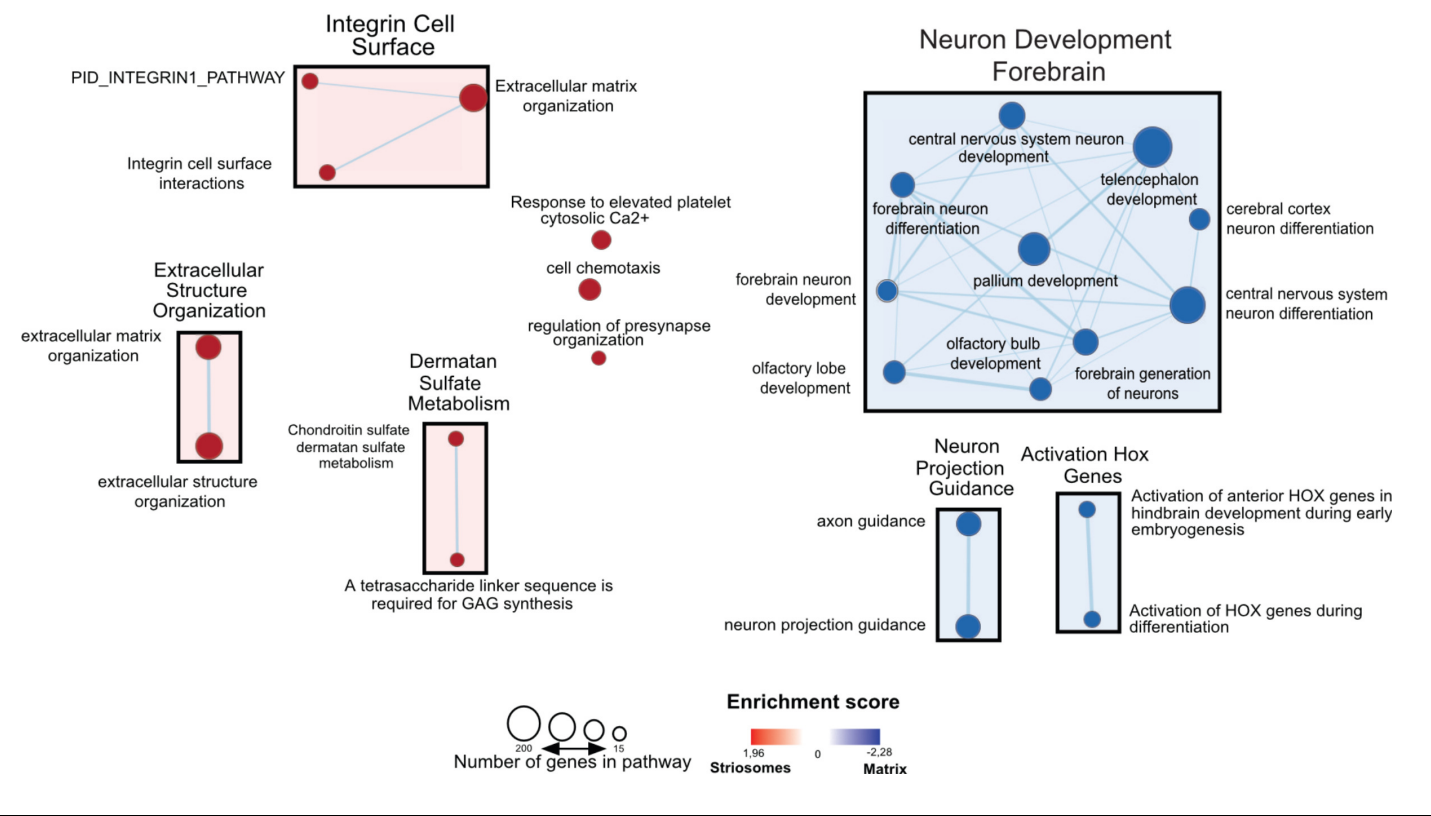

Figure 3. Transcription networks and enrichment maps of striosome and matrix. (A,B) TF networks enriched in either striosome or matrix show interactions and co-expression among the regulatory genes. An arbitrary threshold of absolute log2 fold-change $>$ five was set to designate hub genes. $(C, D)$ Co-expression networks derived from striosome and matrix RNA-seq data show targets of Olig2 and Foxf2 are co-regulated in the striosome. Figure 3 continued on next page 
Figure 3 continued

Genes with higher connectivity to other target genes are designated as hub genes. (E) Pathway and network enrichment (GO-BP) for the striosome (left, red) and matrix (right, blue). The resulting enrichment map was annotated using the AutoAnnotate Cytoscape App.

dramatic enrichment of consensus binding sequences recognized by bZip (Atf3, Jun, Fos) and HMG (Sox) family TFs. On the other hand, motifs recognized by Homeobox (Dlx1, Dlx2) TF family were enriched in the EGFP- OCRs (Figure 4E-H) The known list of TFs identified by Homer are provided as Figure 4-source data 3. Next, we used TOBIAS (Bentsen et al., 2020) to directly assess the differential occupancy and binding of TFs in striosome and matrix OCRs. The differential footprinting analysis revealed a clear enrichment for bZip family (Fos-Jun) at EGFP+ OCRs and homeobox family at EGFP-OCRs (Figure 4I). Annotation of 'FosJunD'-bound regions identified 365 potential genes directly regulated by this TF family. We employed ChEA software (Lachmann et alo, 2010) to integrate our data with ChIP-chip, ChIP-seq, ChIP- PET, and DamID databases. Interestingly, potential FosJunD target genes are over-represented in Olig2-ChIP ( $p$-value=1.482E-12), suggesting that those TFs functionally cooperate in the striosomes, in agreement with RNA-seq based network analysis. We also employed ANANSE (ANalysis Algorithm for Networks Specified by Enhancers, https:// github.com/vanheeringen-lab/ANANSE; Xu et alo, 2021) to define an atlas of key transcription factors required for cell fate determination. The top 15 TFs included Sox10, Olig1, Olig2, Epas1, Sox8, Foxf2, Sox6, Nr4a1, Etv4, Ets1, Nkx2-2, Tcf7l2, Foxc1, and Stat3 (Figure 4-figure supplement 1).

\section{Foxf2 deletion impairs striosome compartmentation and overexpression induces compartmentation and MSN maturation}

Foxf2, noted above to be a hub gene (Figure 3) and highly enriched in the EGFP+ fraction, is a member of the Fox family of TFs that regulate the expression of genes involved in embryonic development, as well as in the adult. Foxf2 is expressed in brain endothelial cells and is critical for elements of craniofacial and cochlear development (Bademci et al., 2019; Hupe et alo, 2017). We confirmed that Foxf2 protein colocalizes to a large degree, but not perfectly, with DARRP-32 striosomes on PND3 (Figure 5A), as do the mRNAs (Figure 5B), and DARPP-32-independent Foxf2 vascular localization is also visualized in both. Foxf2 mRNA and protein are undetectable in adult striatal neurons (Figure 5-figure supplement 1A). Foxf2 deletion is postnatal lethal, so to determine the role of Foxf2 in striosome compartmentation, we analyzed wild-type and Foxf2-null [knockout (KO)] mice at E18.5 by immunohistochemistry (IHC). Indeed, DARPP-32 and TH immunostaining revealed that striosomes were absent in the Foxf2 $\mathrm{KO}$ mice (Figure 5C). Moreover, although the expression level of DARPP-32 was decreased (Figure 5D), the presence of diffuse DARPP-32-immunopositive cells in the striatum of E18.5 Foxf2-null mice (Figure $5 \mathrm{C}$ ) suggests that the early born MSNs migrate to the striatal mantle, but other elements required for striosome organization are impacted. In fact, expression of some of the members of the Eph/Ephrin signaling system associated with control of brain cytoarchitecture (Cooper et alo, 2009; Dufour et al., 2003; Janis et alo, 1999; Kim et al., 2016; Tai and Kromer, 2014) is reduced in Foxf2 KO mice (Figure 5D).

Conversely, endogenously regulated, early overexpression of Foxf2 in a BAC transgenic (Reyahi et al., 2015) leads to a $40 \%$ increase in total striosomal area at PND3 (Figure 5E,F), and to an increase in expression in some, but not all, striosome markers (Figure 5G). The changes in gene expression levels are largely not maintained in the adult (Figure 5-figure supplement 1B), consistent with the lack of expression of Foxf2 in the adult MSNs (Figure 5-figure supplement 1A). The extended overexpression of Foxp2, however, implies an element of a long-lasting effect on striosomes.

We also assayed the effect of Foxf2 on MSN maturation in vitro. Similar to early postnatal striatum in vivo, adenoviral-mediated overexpression of human FOXF2 promoted an increase in the percentage of DARPP-32-immunopositive cells in primary mouse neuronal cultures derived from embryonic striatum (Figure 5-figure supplement 2A) There was also an increase in striosome (Oprm1, Foxp2, Rasgrp1) and matrix (Calb1, Rasgrp2, and EphA4) marker mRNAs in wild-type primary striatal neurons transduced with ADV-FOXF2-mCherry (Figure 5-figure supplement 2A), again suggesting that Foxf2 likely has an effect on overall striatal development, not restricted to striosomes. 
A

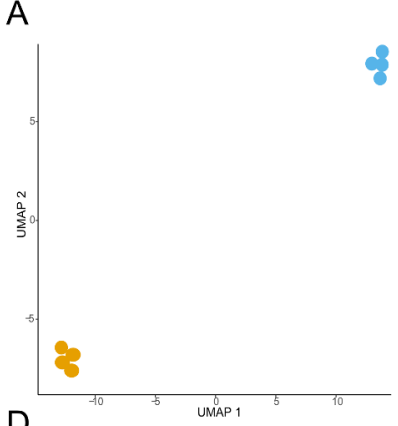

B

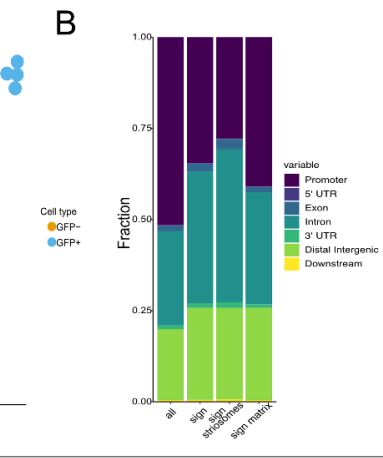

C

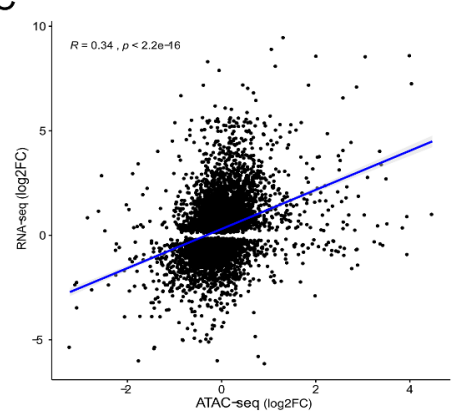

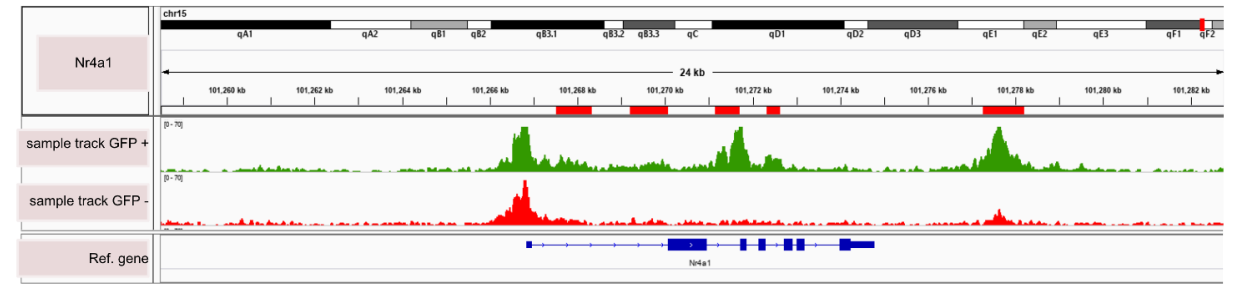

$E$

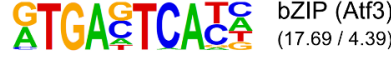

AAACGCCTCCITT

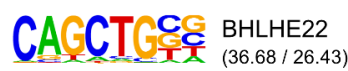

$\mathrm{F}$

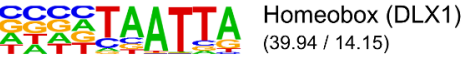

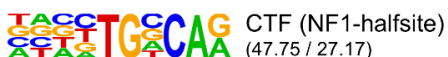

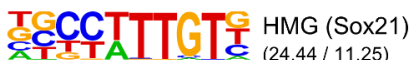

G

Atf3 motif distribution near EGFP+ ${ }^{+}$peaks $\quad H \quad$ Dlx1 motif distribution near EGFP- peaks

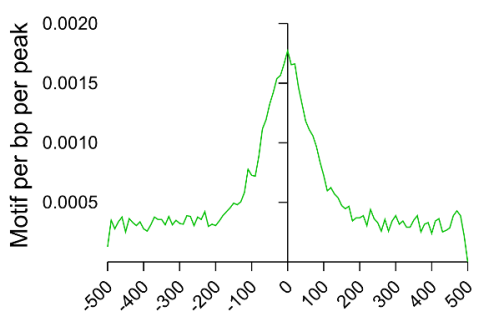

Distance form GFP+ peaks (bp)

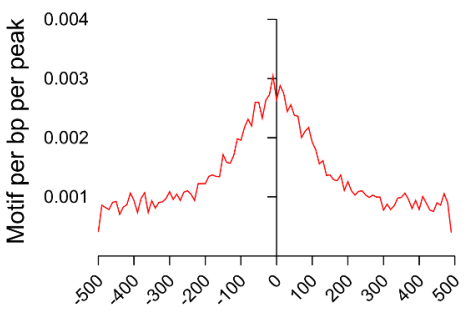

Distance form GFP- peaks (bp)

।

Higher scores in matrix

Higher scores in striosomes

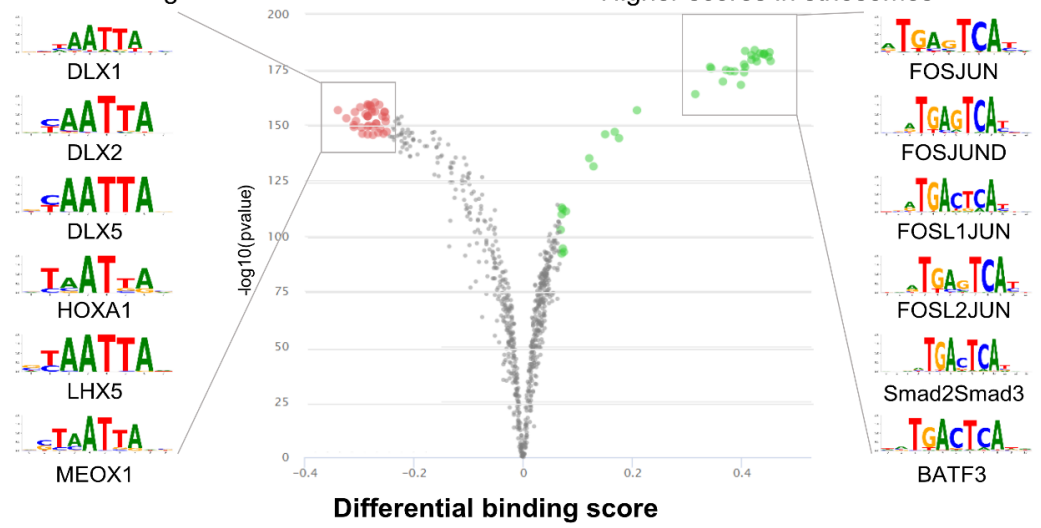

Figure 4. Open chromatin region (ATAC-seq) analysis identifies OCRs differentially located in striosome or matrix. (A) Clustering of the individual samples using UMAP. (B) Distribution of the location within the gene (see Materials and methods, Annotation of OCRs) of all and differentially distributed OCRs. (C) Correlation of log2 fold-changes in RNA-seq and ATAC-seq analyses. OCRs within TSS were considered for this analysis, and only genes with adjusted $p$-value $<0.01$ from RNA-seq analysis were included. (D) Nr4a1 ATAC-seq tracks in EGFP-positive and -negative populations Figure 4 continued on next page 
Figure 4 continued

showing the presence of multiple, possible striosome 'specific' Nr4a1 regulatory elements indicated by the red boxes in the gene annotation. (E,F) Motif analysis of OCRs in striosome (E) and matrix (F). Position weight matrix of enriched nucleotide sequence, the TF family that matches with the motif, and the predicted binding TF are shown. The values in parentheses indicate the percentage of the input sequences that contain the motif relative to the percentage of total background regions filtered by p-value of 0.01 . (G, H) Frequency of predicted binding sites for Atf3 (left) and Dlx1 (right) as a function of distance from the center of striosome and matrix OCRs. (I) Pairwise comparison of TF activity between striosome and matrix. The volcano plots show the differential binding activity against the -log10(pvalue) of the investigated TF motifs; each dot represents one motif. For striosome-specific factors, the significant TFs are labeled in green, whereas matrix-specific factors are labeled in red. The online version of this article includes the following source data and figure supplement(s) for figure 4:

Source data 1. Uniquely mapped reads following ATAC seq of Nr4a1-EGFP+ and Nr4a1-EGFP- cells.

Source data 2. Comparison of striosome (Nr4a1-EGFP+) vs matrix (Nr4a1-EGFP-) peaks representing $44 \%$ of the total number of OCRs which remained statistically significant after multiple testing corrections.

Source data 3. Transcription factors identified by HOMER which putatively bind to enriched binding motifs in Nr4a1-EGFP+ and Nr4a1-EGFP- cells.

Figure supplement 1. Analysis with ANANSE integrating RNAseq and ATACseq identifies key TFs required for striosome MSN differentiation.

\section{Olig2 deletion impairs striosome compartmentation}

Next, we evaluated the role of Olig2 in the developing striosome compartment, including the validation of an associated striosome-specific OCR peak. On PND3, Olig2 protein co-localizes with DARPP-32 in striosomes, and individual Olig2-immunopositive cells devoid of DARPP-32 signal are visible throughout the striatum, likely representing oligodendroglial lineage cells (Figure 6A). We confirmed this distribution using two antibodies raised against Olig2, including one previously validated in Olig2-null mice (Wichterle et al., 2002; Figure 6-figure supplement 1A). Olig2 mRNA also largely colocalized with DARPP-32 mRNA in striosomes (Figure 6B). Note in the IHC that Olig2 protein is cytoplasmic in distribution in the striosomes, but is nuclear in the non-neuronal cells.

To determine if the ATAC-seq identified functional, compartment-specific OCRs distinct from promoters, we sought to validate a putative enhancer peak in a gene preferentially expressed in the striosomes. We compared the Olig2 ATAC-seq tracks from EGFP+ and EGFP- cells and identified a peak $4.4 \mathrm{~kb}$ downstream of the Olig2 gene (Figure $6 \mathrm{C}$ ). We cloned the putative Olig2 enhancer (chr16:91,233,041-91,234,111) into an mCherry reporter plasmid containing only the core hsp68 promoter (Hauberg et al., 2020; Figure 6-figure supplement 1A) and obtained 14 positive founders after pronuclear injection. mCherry was expressed in 9/9 founders on PND3 and co-localized with DARPP-32 neurons in the striosome (Figure 6D). mCherry was also expressed in individual cells in the matrix which are DARPP-32-negative (indicated by arrowheads), and probably again represent cells of the oligodendroglial lineage. The transgenic reporter was expressed in $2 / 5$ founders assayed as adults, but its expression was low and absent in $\mathrm{NeuN}+$ neurons (Figure 6-figure supplement $1 C, D)$.

To determine if Olig2 is required for striosome compartmentation, we utilized a mouse in which a Cre recombinase cDNA inserted into the Olig2 gene leads to a functional knockout (JAX 025567) (Zawadzka et al., 2010). Homozygote animals survived until late on the day of birth, so brains were assayed early on the day of birth. Remarkably, striosomes were absent, particularly in the anterior striatum (Figure 6E). DARPP-32 immunopositive neurons were essentially undetectable in the Olig2 P0-null striatum, and although we have not yet identified the exact mechanism, the data suggest either regulation of Ppp1r1b gene expression by Olig2 and/or failure of striosome neurogenesis or migration. Quantitation of striosome and matrix markers in these mice revealed a marked decrease in Ppp1r1b, Oprm1, and Foxp2 (Figure 6F). We also performed intracerebroventricular injection of AAV-CMV-Olig2-IRES-EGFP on P0, and analyzed the effect of Olig2 overexpression on MSN markers, and surprisingly, found a decrease in Oprm1 and Foxp2 mRNAs, but an increase in Rasgrp1 (Figure 6-figure supplement 1E,F), indicating a mixed effect on the striosomes, which requires further exploration.

Next, we sought to determine if expression of OLIG2 in mouse primary MSNs promotes maturation toward a striosome phenotype (Figure 6-figure supplement 2A,B). Adenovirus-mediated expression of OLIG2 does not increase the number of DARPP-32-immunopositive cells, but importantly, it increases levels of the mRNAs for striosome markers Oprm1, Foxp2 and Rasgrp1. 
A

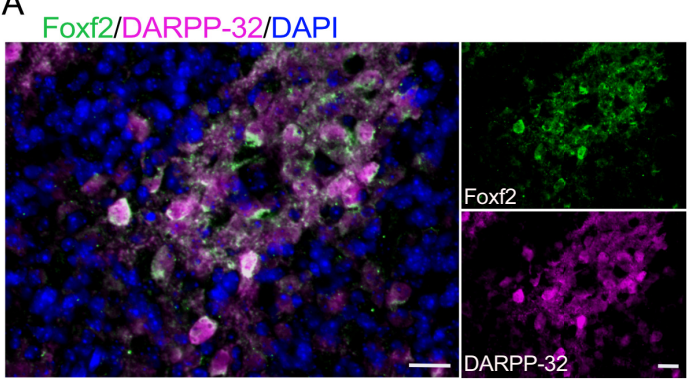

C

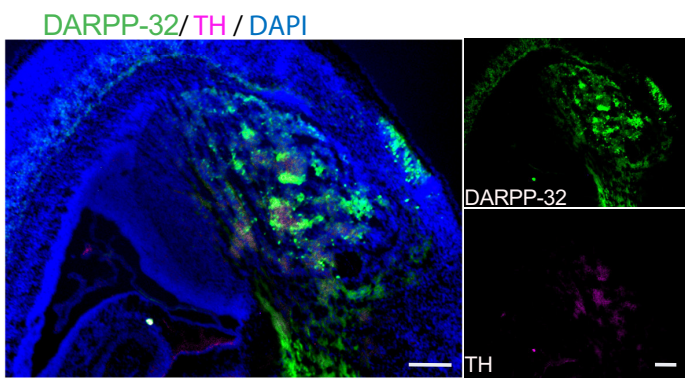

E18.5 WT

D
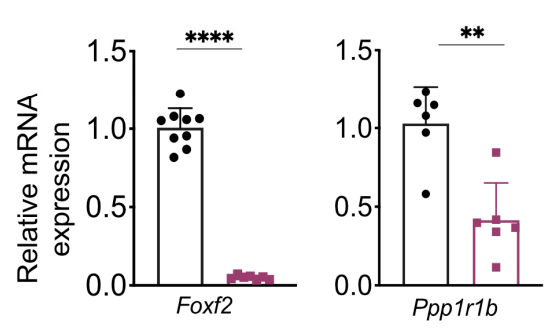

E

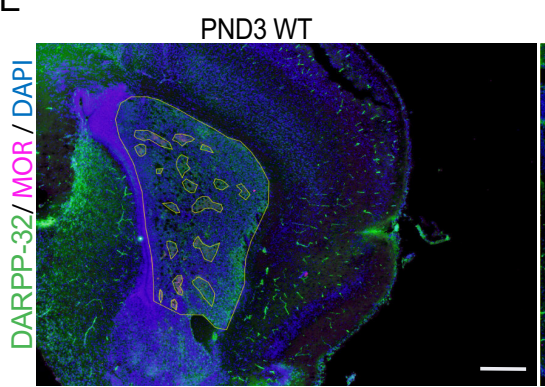

G

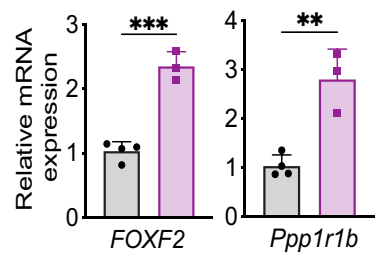

B

Foxf2 mRNA/DARPP-32 mRNA/DAPI

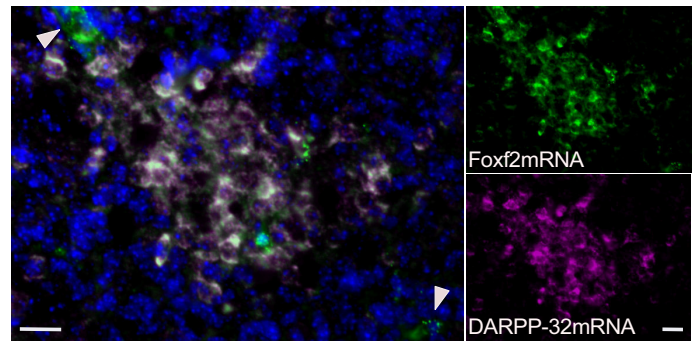

DARPP-32/TH / DAPI

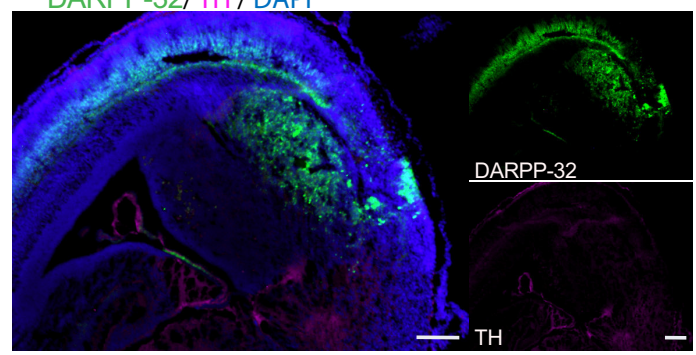

E18.5 Foxf2 KO 
Figure 5 continued

mRNA. Scale bars $=20 \mu \mathrm{m}$. (C) DARPP-32 (green) and tyrosine hydroxylase (TH) (magenta) immunostaining in sagittal sections of E18.5 WT and Foxf2 $\mathrm{KO}$ mice show the absence of striosome assembly in Foxf2 KO mice. Scale bars $=100 \mu \mathrm{m}$ (D) RT-qPCR from E18.5 Foxf2 WT and null littermates striatal RNA indicating that Foxf2 expression was abolished in the null mouse and that the levels of Ppp1r1b and Efna5 mRNA were significantly reduced by Foxf2 deletion. $\mathrm{n}=7$ Foxf $2^{--}$and $\mathrm{n}=9 \mathrm{WT}$. Unpaired t-test ${ }^{* \star} \mathrm{p}<0.001,{ }^{* \star * *} \mathrm{p}<0.0001$. Error bars $=$ standard deviation. (E,F) Comparison of area occupied by striosomes identified by merged DARPP-32 (green) and MOR (magenta) immunolabeling of $16-\mu$ m-thick coronal sections from PND3 WT and overexpressing Foxf2 (Foxf2 BAC $\mathrm{Tg}^{(+/+)}$) littermates showing an increase of striosome density (highlighted) mediated by Foxf2 overexpression. $\mathrm{n}=$ three individual mice per genotype. Unpaired t-test ${ }^{*} \mathrm{p}<0.05$. Error bars $=$ standard deviation. (G) RT- $q \mathrm{PCR}$ assay shows increase in the expression of both striosome (Ppp1r1b, Oprm1, Foxp2) and matrix (Rasgrp2) markers in the striatum of PND3 mice overexpressing Foxf2. $\mathrm{n}=$ three mice per genotype. Unpaired t-test ${ }^{*} p<0.05,{ }^{* *} p<0.01,{ }^{* *} p<0.001$. Error bars represent standard deviation.

The online version of this article includes the following figure supplement(s) for figure 5 :

Figure supplement 1. Foxf2 mRNA is undetectable in adult striatum but Foxf2 overexpression increased the level of FoxP2 mRNA in PND21 Foxf2 BAC $\operatorname{Tg}^{(+/+)}$striatum.

Figure supplement 2. Foxf2 overexpression in medium spiny neurons promote their maturation in vitro.

\section{Transcription network analysis defines the STAT pathway as a key regulator of striosome development}

We used the arithmetic mean of the rank of each of the TFs at each node to quantitatively assess the importance of individual TFs in the striosome network (Figure 3A). The ranking was based on the number of edges expanding from each node and the number of overlapping TFs shared between nodes that interact with Nr4a1. Among the $58 \mathrm{TFs}$ in the striosome network, the average rank of Stat3 is 4.5 , which ranks at the top. We also built the gene regulatory network, including all differentially expressed TFs, set through the regulatory data curated by ORegAnno database (Lesurf et al., 2016), which identified Stat1 as the TF that regulated the greatest number of differentially expressed TFs (314 out of 811) (Figure 7A). Both Stat1 and Stat3 are enriched in the EGFP+ cells (Figure 2-source data 1), so together with the in-silico analyses, these data suggest that the STAT pathway is a key regulating pathway during the differentiation of striosome neurons. To test this hypothesis, we expressed human STAT1 in primary mouse MSNs. STAT1 overexpression increased the number of DARPP-32-immunopositive cells (Figure $7 B, C$ ) and increased the mRNA levels of striosome markers Ppp1r1b, Oprm1, Foxp2, Foxf2, and Olig2, as well as the matrix marker Calb1 (Figure 7D). Particularly notable is the upregulation of Foxf2 and Olig2, suggesting that these two TFs may be downstream of Stat1.

\section{TFs drive MSN fate in iPSCs-derived neural stem cells (NSCs)}

MSN subtypes are critically needed for disease modeling, and protocols and TFs that specifically drive a striosome phenotype are just beginning to emerge (Cirnaru et al., 2019). To determine if the FOXF2, OLIG2, and STAT pathways are key for human development of MSNs and represent useful TFs for disease modeling of MSN subtypes, we expressed the TFs alone or in combination in NSCs derived from HD patient-induced pluripotent stem cells (Figure 8; An et al., 2012; Naphade et al., 2017; Ring et al., 2015; Voisin et al., 2020; Zhang et al., 2010). STAT1 overexpression, with or without FOXF2, increases the number of OPRM1-immunopositive cells (Figure 8A), with OLIG2 producing a trend in the same direction. STAT1 and OLIG2 together also increase the expression of PPP1R1B (Figure 8A,B). Alone, only OLIG2 increases RASGRP1 and EPHA4 mRNAs, but in combination, STAT1 and FOXF2 induce RASGRP1, although to a lesser extent. Interestingly, RASGRP2, a marker of the matrix, largely behaves inversely to RASGRP1, consistent with their expression in vivo.

OLIG2 alone also increases the matrix marker CALB1 mRNA, but at a lower-fold than the striosome markers. Notably, in contrast to its effect in primary MSNs, FOXF2 alone increased only RASGRP2, and did not even increase TUJ1, a marker of pan-neuronal differentiation. Along with the in vivo absence of striosome compartmentation in the striatum despite the presence of Ppp1r1b neurons, these data may indicate an early role restricted to compartmentation and not overall phenotypic maturation as defined by expression of gene markers. In agreement with this hypothesis, FOXF2 alone failed to induce expression of BCL11B mRNA, a transcription factor required for striatal development (Arlotta et al., 2008). As expected, expression of FOXF2, OLIG2 and STAT in HD NSCs resulted in an increase expression of pan neuronal marker Nestin (Figure 8-figure 
A

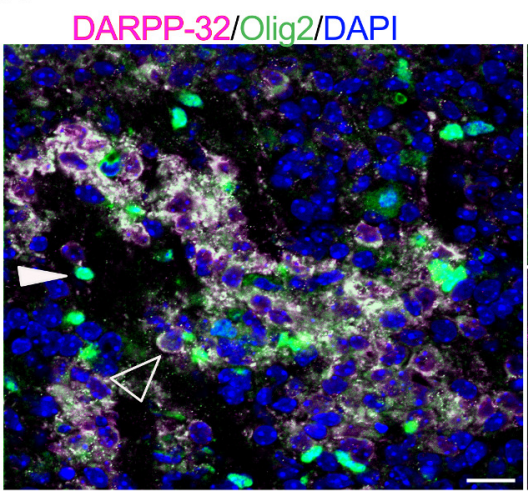

B

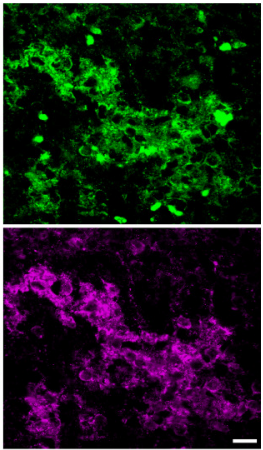

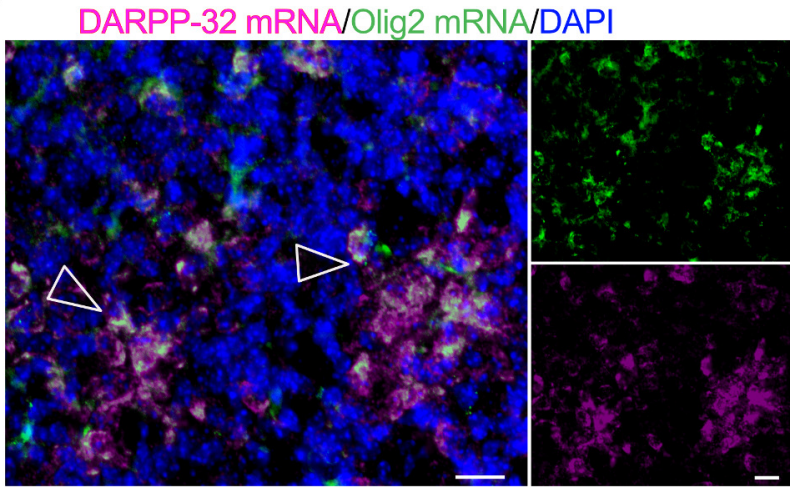

C

D

DARPP-32/mCherry/DAPI
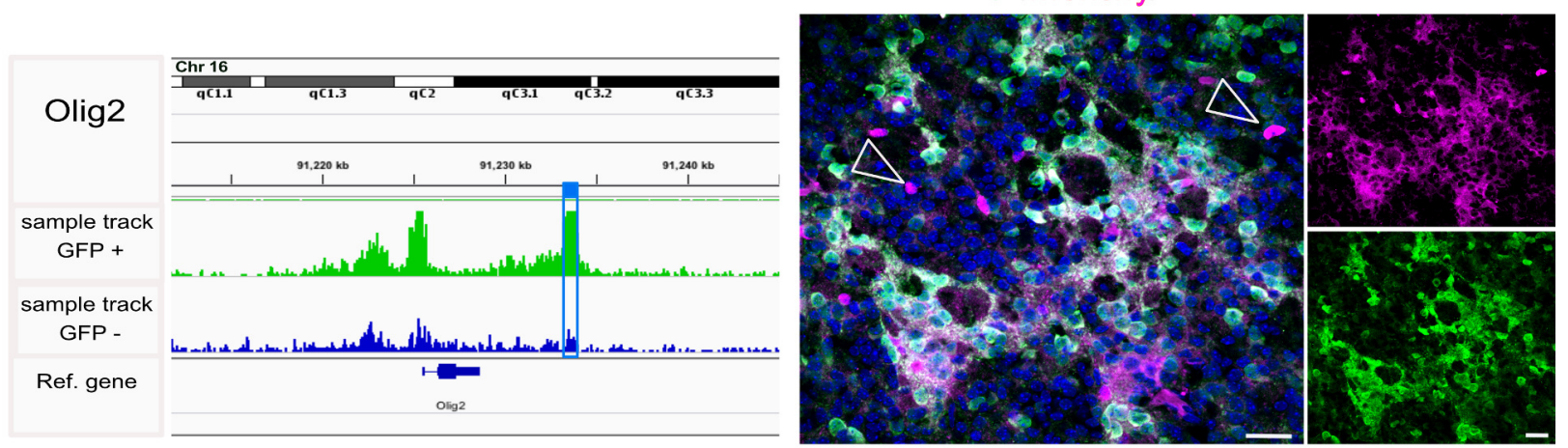

E

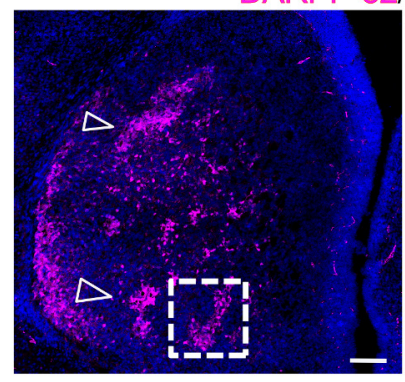

DARPP-32/DAPI

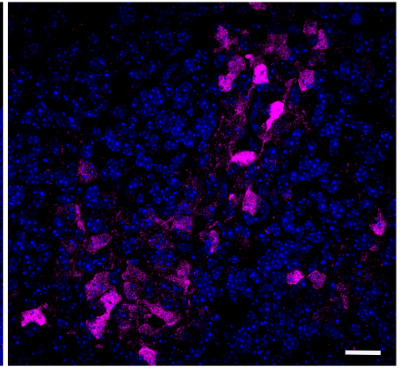

PND0 WT

F
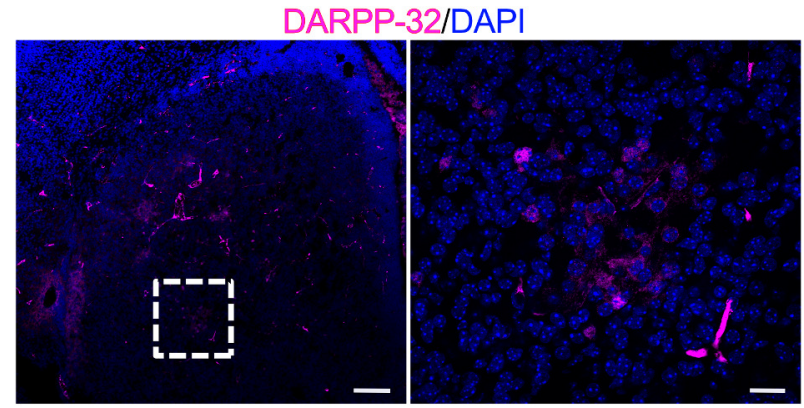

PND0 Olig2 KO

- Wt

- Olig2 KO

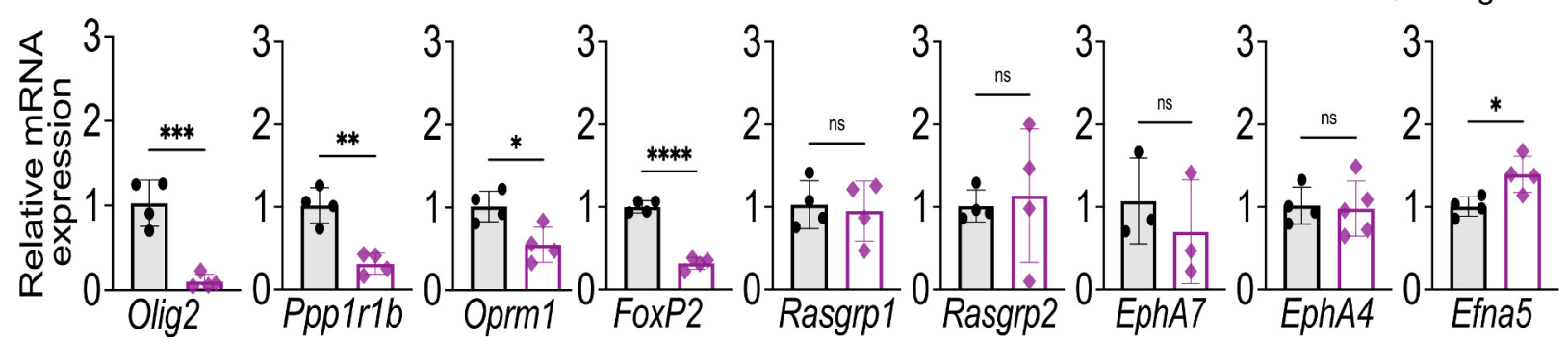

Figure 6. Olig2 is required for striosome compartmentation and a downstream intergenic Olig2 OCR drives transgenic reporter expression in striosomes. (A) Confocal micrographs of Olig2 (green), DARPP-32 (magenta) and DAPI (blue) immunolabeling of WT PND3 16- $\mu$ m-thick coronal sections showing localization of Olig2 within the DARPP-32-positive striosomes (unfilled arrowhead). An examples of a single Olig2-immunopositive and DARPP32-negative cell is indicated by a filled overhead. Scale bars $=20 \mu \mathrm{m}$ (B) RNAscope visualization of Olig2 (green) and Ppp1r1b/DARPP-32 (magenta)

Figure 6 continued on next page 
Figure 6 continued

mRNAs showing colocalization in PND3 wild-type striosomes with individual double-labeled cells highlighted by arrowheads. (C) Olig2 ATAC-seq tracks in $\mathrm{EGFP}^{+}$and EGFP ${ }^{-}$samples from PND3 Nr4a1-EGFP striatum showing the presence of an OCR $4.4 \mathrm{~kb}$ downstream of the Olig2 gene, restricted to $\mathrm{EGFP}^{+}$samples (highlighted by the blue box). (D) Representative confocal micrographs of mCherry (magenta), DARPP-32 (green), and DAPI (blue) immunolabeling of 16- $\mu \mathrm{m}$-thick coronal sections from PND3 Olig2 -OCR transgenic mice showing that the isolated OCR sequence drives expression of the $\mathrm{mCherry} \mathrm{reporter} \mathrm{restricted} \mathrm{in} \mathrm{large} \mathrm{part} \mathrm{to} \mathrm{DARPP-32-immunopositive} \mathrm{neurons} \mathrm{in} \mathrm{striosomes.} \mathrm{Individual} \mathrm{magenta} \mathrm{cells,} \mathrm{examples} \mathrm{indicated} \mathrm{by}$ arrowheads, likely represent cells of the oligodendroglia lineage. Scale bars $=20 \mu \mathrm{m}$. (E) DARPP-32 (magenta) and DAPI immunostaining in coronal sections of PNDO WT and Olig2 KO mice showing a dramatic reduction of DARPP-32-immunopositive neurons and striosome assembly in Olig2 KO mice. Scale bars $=100 \mu \mathrm{m}$ and $20 \mu \mathrm{m}$, respectively. (F) RT-qPCR from striatal RNA from PND0 Olig2 KO and WT littermates indicating that striosome marker mRNAs are decreased in the KO brains. Olig2 ${ }^{-1}, n=5 ; W T, n=4$. Unpaired t-test ${ }^{\star} p<0.05,{ }^{\star \star} p<0.001,{ }^{\star \star \star *} p<0.0001$. Error bars $=$ standard deviation.

The online version of this article includes the following figure supplement(s) for figure 6:

Figure supplement 1. Impact of neonatal AAV2 driven Olig2 overexpression on the striatum of PND21 mice and analysis of Olig2 OCR-driven expression in adult founders.

Figure supplement 2. Olig2 overexpression in medium spiny neurons promote their maturation in vitro.

supplement 1). Similar results were observed in isogenic controls C116-NSCs (Figure 8-figure supplement 2), in which OLIG2/STAT1 clearly induce OPRM1 expression. FOXF2, OLIG2, and STAT expression provides a rapid differentiation of DARPP-32 MSNs with high levels of MOR expression within 4 days. Current MSN protocols require 20-50 days of culture and do not generate striosomal MSN subtypes (Arber et alo, 2015; Golas, 2018; Kemp et al., 2016; Telezhkin et al., 2016; Victor et al., 2014).

\section{Discussion}

In the first postnatal week, striosome neurons are already compartmentalized, and their maturation is relatively advanced as compared to the matrix, based on their description as 'dopamine islands' and their expression of Ppp1r1b/DARPP-32 (Fishell and van der Kooy, 1987; Graybiel, 1984; Mason et al., 2005). We therefore hypothesized that selective sorting of Nr4a1-EGFP+ cells would yield young striosome neurons expressing TFs required for determination of striosome identify and low levels of markers of terminal differentiation, and the second group would be relatively immature EGFP-negative neurons committed to become matrix neurons, but not yet expressing most markers of terminal differentiation (Figure 1). We have previously shown a role for Nr4a1 in striosome development (Cirnaru et al., 2019), but based on the known expression pattern of Nr4a1, we were not anticipating that either set of cells would be purely neuronal. Nr4a1 is expressed in endothelial cells (Liu et al., 2003), the myeloid lineage (Wenzl et al., 2015), OPCs (Li et al., 2015), and upon activation, in astrocytes (Wu et al., 2017).

Foxf2 $(\log 2 \mathrm{FC}=7.9)$ and Olig2 $(\log 2 \mathrm{FC}=3.05)$ have not previously been associated with striatal neuronal development. Foxf2 regulates the expression of Ephrin A5 and to some extent EphA7, both known to guide neuronal migration and connectivity of several brain regions, including striatum (Cooper et al., 2009; Dufour et al., 2003; Lee et al., 2013; Passante et al., 2008; Tai and Kromer, 2014; Washburn et al., 2007). In the context of gut development, components of extracellular matrix are severely reduced in the absence of Foxf2, leading to a lack of epithelial cell polarization and tissue assembly (Ormestad et al., 2006). Foxf2 is also required to establish the cochlear cytoarchitecture (Bademci et alo, 2019) including elements of neuronal innervation and axonal density. In vitro in primary MSNs, increased Foxf2 levels induce genes expressed in striosomes and matrix but not in the less mature hNSCs, which together with the in vivo appearance of the Foxf2null striatum, suggests that Foxf2 alters genes associated with sorting of striosomes and matrix neurons in the embryonic period, and not necessarily with MSN-specific maturation. Notably, the vasculature may play a role in striatal compartmentation, as striosomes appear to have greater vascularization than matrix (Breuer et al., 2005). The importance of blood vessels in the regulation of cortical neuronal migration and maturation is well described (Li et al., 2018; Paredes et al., 2016; Wälchli et al., 2015), so there could be both cell-autonomous and non-cell-autonomous mechanisms via which Foxf2 regulates striatal compartmentation. 


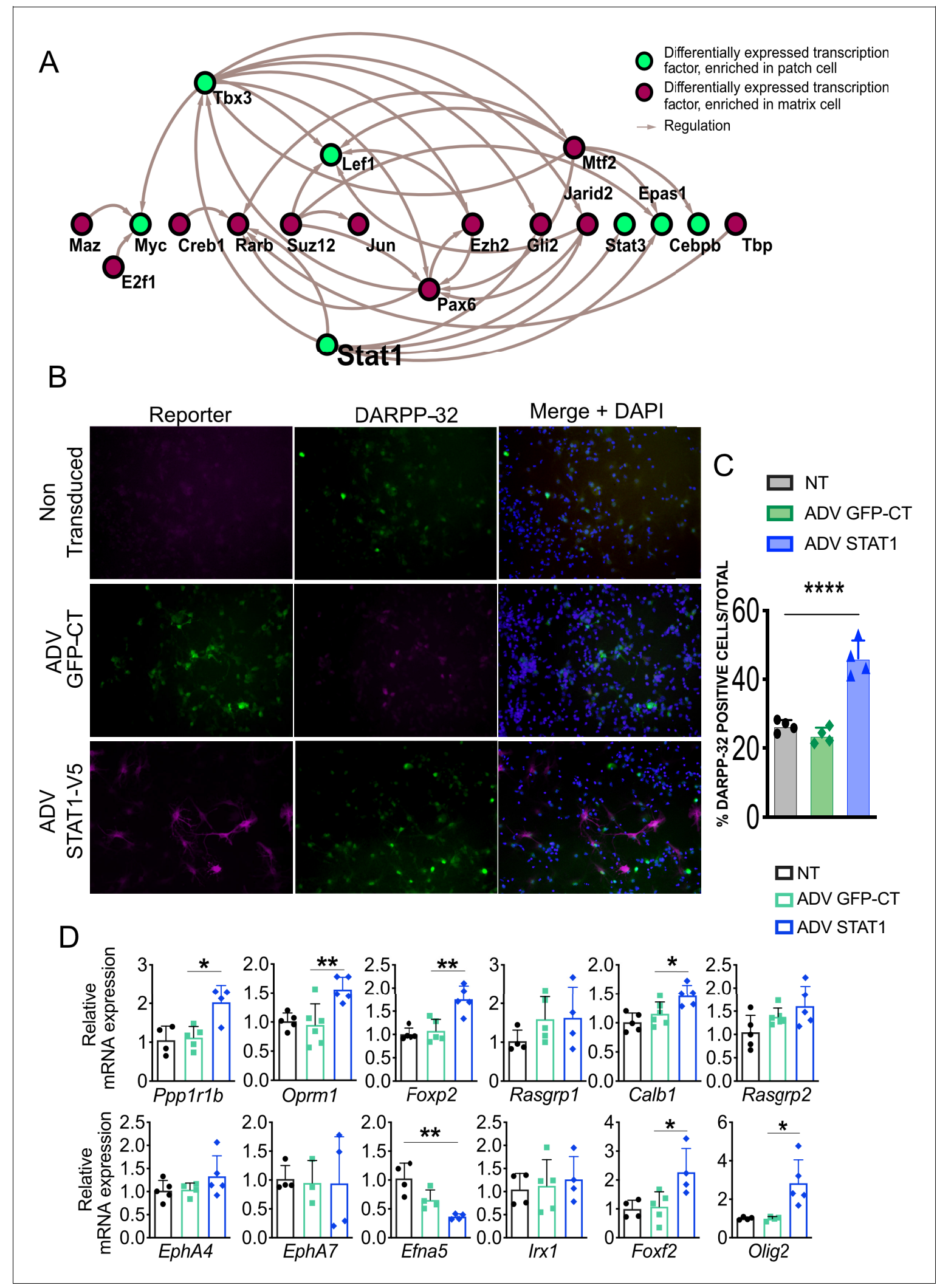

Figure 7. STAT1 overexpression in MSNs in vitro promotes maturation and increases levels of Foxf2 and Olig2 mRNAs. (A) Network analysis indicates that Stat1 may be a 'master' regulator in striosomes as it modulates the levels of the greatest number of TFs enriched in that compartment. (B,C) GFP and DARPP-32 immunolabeling in DIV9 WT primary striatal neurons either non-transduced (NT) or transduced for 96 hr with ADV-STAT1-V5 or ADVGFP showing that STAT1 overexpression increases the number of DARPP-32-immunopositive cells. Scale bars $=50 \mu \mathrm{m}$. $\mathrm{n}=$ four images from four Figure 7 continued on next page 
Figure 7 continued

individual cultures, t-test ${ }^{* \star *} \mathrm{p}<0.001$. (D) RT- qPCR assay shows increase of mRNA for striosome markers Ppp1r1b, Oprm1, Foxp2, Foxf2, and Olig2, matrix markers Calb1 and EphA4 and decrease in striosome enriched EphA7 ligand and Efna5 in DIV9 wild-type primary striatal neurons 96 hr after transduction with ADV-STAT1-V5. $n=$ four individual cultures, one-way ANOVA corrected for multiple comparisons (Bonferroni's) ${ }^{*} p<0.05$, ${ }^{* *} p<0.01$. Error bars $=$ standard deviation.

Olig2 ( $\log 2 \mathrm{FC}=3.05$ ) was not among the most enriched in its group, but both Olig1 and Olig2 are regulators of neuronal subtype development in the human fetal central nervous system (Jakovcevski and Zecevic, 2005), and in mouse, Olig2 is regulated by D/x1 and Dlx2 and appears to be involved in the neuron-glial switch (Petryniak et al., 2007). Specifically, Olig2 participates in the development of GABAergic neurons in the pre-thalamus and thalamus (Inamura et al., 2011; Ono et al., 2014; Wang et al., 2011a). Olig2 is included in the triplicated region in the Ts65Dn mouse, with marked effects on brain development in multiple regions and in iPSCs, including an increase in GABAergic interneurons (Chakrabarti et al., 2010; Xu et al., 2019). Notably, Olig2 is highly localized to the cytoplasm in striosome neurons, similar to its localization in astrocytes where it acts to regulate differentiation (Setoguchi and Kondo, 2004). The validation of the predicted OCR in the Olig2 gene as a striosome-specific enhancer in the striatum lends further support to the function of Olig2, while highlighting the value of the ATAC-seq database.

The use of these new data bases to construct a transcriptional regulatory network also led to the identification of Stat1/3 as TFs able to modulate striosome and matrix phenotypes. Notably, these two members of the Stat gene family dimerize with each other (Delgoffe and Vignali, 2013). Neither Stat 1 nor Stat3 has been associated with MSN development, but they are reported to promote neuronal differentiation (Wei et al., 2014). Further work is required to determine the role of Stat 1 in striatal development in vivo, but we did find a clear maturation effect in vitro. The effects of validated TFs on members of the ephrin family highlight the fact that, although we focused on TFs, these data sets also identify compartment-enriched mRNAs encoding proteins other than TFs that are likely critical for establishing and maintaining striatal compartmentation. For the two TFs that we validated in detail, Foxf2 and Olig2, their functions do not appear to include maintenance of striosome identity, as their expression is undetectable in adult mouse MSNs, and there are no assigned striatal ATAC-seq peaks from human adult striatum (Fullard et al., 2018).

The transcription regulatory networks generated for each cell compartment have defined other potential TFs and pathways regulating striosome and matrix cell fate. The co-expression enrichment analysis highlighted a set of TFs that coexist with Foxf2, including Sox7, Sox17, Sox18, PrrX1, Tead2, Bcl6, Klf4, Egr2, and Tbx2. Other than Tead2 and Tbx2, these TFs are enriched in the EGFP+ cells. Sox 17 belongs to the Sox family of TFs that regulates oligodendrocyte progenitor cell expansion and differentiation during development and repair via Notch signaling (Chew et al., 2019). Both Sox17 and Notch signaling regulate TCF7L2 expression (Chew et al., 2019), which is enriched in the same compartment. TCF7L2 regulates calcium signaling (Ye et al., 2020), a function associated with both gene sets. In spinal cord patterning, TCF7L2 in partnership with Tcf4 represses Olig2 expression by recruiting HDAC activity and is required for cell-fate specification (Wang and Matise, 2016). Histone deacetylase activity likewise plays a role in MSN maturation (Chandwani et al., 2013). For Olig2, the TF co-expression network highlights Etv5, Mitf, Egr2, Sox10, Olig1, Hey1, and Arnt/2, which are also mostly enriched in the EGFP+ compartment. There is considerable evidence of cooperation between Olig2 and Olig1 in other systems, including neuronal cells (Kim et al., 2011). Thus, detailed analyses of these databases point to multiple TF networks likely to be involved in striosome development.

Consistent with our hypothesis, the EGFP- cells were indeed enriched in markers of immature MSNs. Most notably, these included multiple members of the Dlx family, required for patterning and differentiation (Long et al., 2009), Is/1 which promotes commitment of striatonigral neurons (Ehrman et al., 2013), and markers of neuronal differentiation but not specifically related to the striatum, e.g., Sox 11 and Pax6, the latter of which is expressed in the ventricular zone of the lateral ganglionic eminence (Puelles et al., 2000). The Arx family is involved in neuronal progenitor proliferation and was identified by its association with lissencephaly syndromes, some of which have specific basal ganglia deficits (Fulp et alo, 2008). Eomes/Tbr2 is associated with cortical development, as is $T b r 1$, raising the possibility of contamination by cortical elements during dissection and 


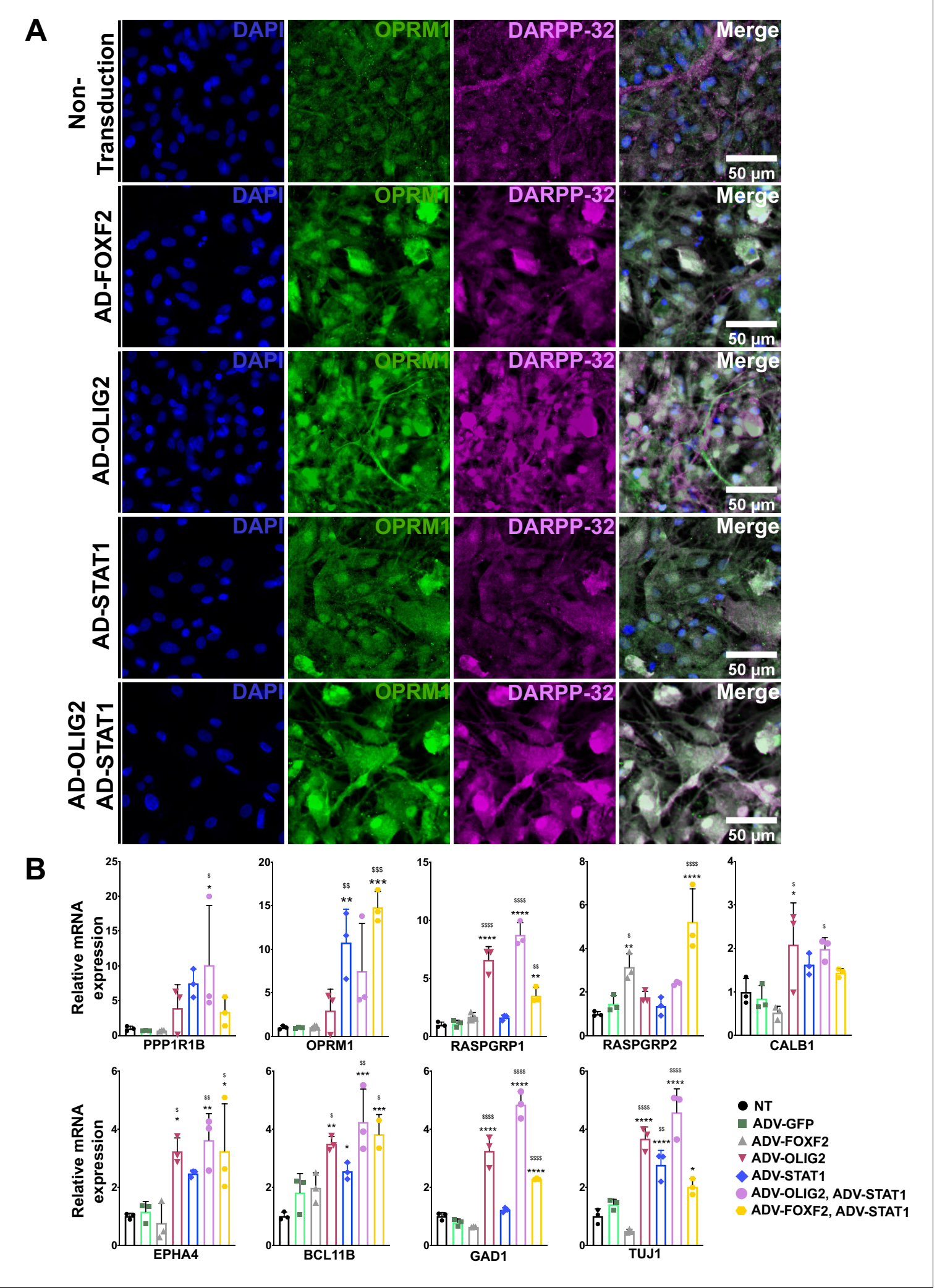

Figure 8. FOXF2, OLIG2, and STAT1, alone and in combination, promote MSN differentiation in NSCs from human HD induced pluripotent stem cells. (A) HD72-NSCs transduced for 4 days with ADV-FOXF2, ADV-OLIG2 and ADV-STAT1 were immunostained with Oprm1 (green) and DARPP-32 (magenta). Non-transduced cells and AD-GFP were used as control. Scale bars $=100 \mu \mathrm{m}$. (B) RT-qPCR assay on HD72-NSCs transduced for 4 days with ADV-GFP, ADV-FOXF2, ADV-OLIG2 and ADV-STAT1. $\mathrm{n}=$ three individual cultures. One outlier (one of the three technical data points) was excluded in Figure 8 continued on next page 
Figure 8 continued

Bcl11b RT-qPCR when transduced with ADV- FOXF2 and ADV-STAT1. One-way ANOVA for multiple comparisons (Dunnett's) ${ }^{*} p<0.05,{ }^{* *} p<0.01$,

${ }^{* * *} p<0.001,{ }^{* \star * \star} p<0.0001$. ${ }^{*}$ for comparison to non-transduced and for comparison to ADV-GFP. Error bars are standard deviation.

The online version of this article includes the following figure supplement(s) for figure 8:

Figure supplement 1. Expression of FOXF2, OLIG2 and STAT in HD NSCs resulted in an increase expression of pan neuronal marker Nestin in HD NSCs.

Figure supplement 2. FOXF2, OLIG2, and STAT1, alone and in combination, promote MSN differentiation in NSCs from human isogenic control C116induced pluripotent stem cells.

cell selection (Puelles et al., 2000). Notably, however, both Tbr1 and Satb2 mRNAs are detected in the striatum [Allen Mouse Brain Atlas (mouse.brain-map.org)]. Interestingly, Foxp2 and Oprm1 are associated with striosomes (Campbell et al., 2009) but are enriched in the EGFP- cells. These data imply that, in some cases, transcription and translation may be dissociated at this stage. Indeed, Oprm 1 mRNA distribution is initially diffuse during striatal development (Tong et al., 2000) and the Allen Brain Atlas fails to confirm a striosome distribution for Foxp2 at this age.

In summary, we present two data bases derived from PND3 striatum that compare gene expression and OCRs in developing striosome and matrix, demonstrating clear gene expression and epigenetic distinctions. Using these data sets, we describe a novel pathway via which Stat1 appears to regulate a transcriptional hierarchy that includes Foxf2 and Olig2, critical for striosome compartmentation and phenotypic maturation. Further, we demonstrate that these TFs can be utilized to better model striatal striosome MSNs in hiPSC systems and to develop genetic tools to direct expression to neuronal subsets for their eventual in vivo manipulation and study.

\section{Materials and methods}

\section{Animals}

Animal procedures were conducted in accordance with the NIH Guidelines for the Care and Use of Experimental Animals and were approved by the Institutional Animal Care and Use Committee of our institutions (LA09-00272, 16-0847 PRYR1). The Nr4a1-EGFP mice used for this study were obtained from GENSAT and the Olig2-Cre mice were obtained from Jackson Laboratories. All recombinant Foxf2 mice were kindly provided by Dr. Peter Carlsson. Mice were given ad libitum access to food and water and housed under a $12 \mathrm{hr}$ light/dark cycle. Both male and female mice were used in these studies.

\section{Enzymatic dissociation and FACS purification of striatal neurons}

PND3 Nr4a1-EGFP heterozygous mice were obtained from a time set homozygote Nr4a1-EGFP bred to WT pairs. The pups were separated by sex and rapidly euthanized by decapitation, and the striata dissected under the microscope in ice-cold Hibernate-A medium (A1247501, Gibco, Thermo Fisher). The striata were collected from three PND3 mice per sample and exposed to enzymatic dissociation with papain (Lobo et al., 2006) with minor modification. Briefly, the tissue was incubated with frequent agitation at $37^{\circ} \mathrm{C}$ for $20 \mathrm{~min}$ in $2 \mathrm{ml}$ of $2 \mathrm{mg} / \mathrm{ml}$ papain (Sigma, P4762) solution in Hibernate-A. The tissue was washed twice with $5 \mathrm{ml}$ of Hibernate-A, including $1 \mathrm{mg} / \mathrm{ml}$ protease inhibitor (Thermo Fisher, 78442), and briefly triturated in $2 \mathrm{ml}$ of Hibernate-A medium using fire-polished glass Pasteur pipettes until a single-cell suspension was obtained. The cell suspension was filtered through $70 \mu \mathrm{m}$ mesh previously equilibrated with $2 \mathrm{ml}$ of Hibernate-A. The cells left on the filter were collected by washing the filter with $1 \mathrm{ml}$ of Hibernate-A. The cells were centrifuged for 5 $\mathrm{min}$ at $700 \mathrm{~g}$ and treated for $10 \mathrm{~min}$ with DAPI (4',6-diamidino-2-phenylindole) (1:4000, Sigma, 62248)to label dead cells. The cells were washed with $10 \mathrm{ml}$ of Hibernate-A, centrifuged for $5 \mathrm{~min}$ at $700 \mathrm{~g}$ and resuspended in $0.35 \mathrm{ml}$ of Hibernate-A. Viable cells (DAPI negative) were sorted and collected into two populations: EGFP+ and EGFP- using a BD Influx FACS sorter based on fluorescein5-isothiocyanate (FITC) channel signal for EGFP. WT striatal cells were used to calibrate the FITC and DAPI signals. The cells for RNA-seq (1000 cells/sample) were collected in $150 \mu$ of Arcturus PicoPure extraction buffer. After the sorting, the samples were incubated at $42^{\circ} \mathrm{C}$ for 30 min and stored at $-80^{\circ} \mathrm{C}$ until RNA extraction was performed using Arturus PicoPure RNA Isolation kit 
(Applied Biosystems, 12204-01). The cells for ATAC-seq (25,000 cells/sample) were collected in 1.5 $\mathrm{ml}$ Eppendorf tubes coated with $5 \%$ BSA, centrifuged at $300 \mathrm{~g}$ for $10 \mathrm{~min}$ at $4^{\circ} \mathrm{C}$, and the pellet was stored.

\section{Tissue preparation and immunofluorescence}

PND3 mice were rapidly euthanized by decapitation, and brains were removed, washed in ice-cold PBS, and post-fixed for $24 \mathrm{hr}$ at $4^{\circ} \mathrm{C}$ in $4 \%$ PFA. The brains were then incubated in $30 \%$ sucrose/1X PBS for $24 \mathrm{hr}$ at $4^{\circ} \mathrm{C}$ and cryopreserved in OCT embedding medium (4583, Tissue-Tek Sakura). Serial coronal sections $(16 \mu \mathrm{m})$ were cut on a Leica cryostat, collected on Superfrost Plus microscope slides (Fisher Scientific) and frozen at $-20^{\circ} \mathrm{C}$. Immunofluorescence was performed as described (Cirnaru et al., 2019). Sections were incubated with mouse anti-DARPP-32 (1:250, sc271111, Santa Cruz Biotechnology), sheep anti-Foxf2 (1:2000, AF6988, R and D), rabbit anti-Olig2 (1:500, ab136253, Abcam), rabbit anti-Olig2 (1:8000, gift from Dr. Wichterle) (Wichterle et alı, 2002), mouse anti-Olig2-Alexa488 (1:1000, MABN50A4, Millipore) rabbit anti-Irx1 (1:2000, PA536256, Thermo Fisher Scientific) or rabbit anti-tyrosine hydroxylase (1:1000, OPA1-04050, Thermo Fisher Scientific) antibodies. The respective secondary antibodies included: anti-mouse Alexa 488 (1:400, A-11008, Thermo Fisher Scientific), anti-mouse Alexa 594 (1:400, A-11005, Thermo Fisher Scientific), anti-rabbit Alexa 488 (1:400, A-11034, Thermo Fisher Scientific), anti-rabbit Alexa 594 (1:400, A-11012, Thermo Fisher Scientific), or anti-sheep Alexa 594 (1:400, A-11016, Thermo Fisher Scientific). Sections were sealed with Vectashield hard-set mounting medium (H-1400, Vector Laboratories). Images were acquired using an Olympus BX61 microscope or a Confocal Zeiss LSM 510.

\section{Fluorescent in situ hybridization (FISH) using RNAscope technology}

Postnatal day 3 WT brains were fixed in freshly prepared, ice-cold $4 \%$ PFA for $24 \mathrm{hr}$ at $4^{\circ} \mathrm{C}$, followed by equilibration in $10 \%$ sucrose gradient, then $20 \%$ and finally $30 \%$, each time allowing the tissue to sink to the bottom of the container. The tissue was embedded in OCT compound (4583, Tissue-Tek Sakura) and stored at $-80^{\circ} \mathrm{C}$ until sectioned. $16 \mu \mathrm{m}$-thick sections were cut using a Leica cryostat, collected onto Superfrost Plus slides maintained at $-20^{\circ} \mathrm{C}$ during the sectioning. The slides were then stored at $-80^{\circ} \mathrm{C}$. RNAscopeProbe murine Mm-DARPP-32-C1 Ppp1r1b (NM_144828.1, bp5901674, 405901), Mm-Olig2-C3 (NM_016967.2, bp865-2384, 447091-C3)and Mm-Foxf2-C2 (NM_010225.2, bp846-2316, 473391-C2) were purchased from Advanced Cell Diagnostics probe catalog (ACD). For signal detection, we used Opal 520 and Opal 690 TSA plus fluorophores (Akoya Biosciences). The RNAscope Multiplex Fluorescent Reagent Kit v2 (ACD, 323100) used here provides the target retrieval solution, hydrogen peroxide, protease III, amplification reagents (Amp1-3), HRP reagents, DAPI, TSA buffer and wash buffer. We used a modified version of the manufacturer's protocol for sample preparation, probe hybridization, and signal detection. Briefly, the fresh frozen sections on slides were retrieved from $-80^{\circ} \mathrm{C}$ and briefly immersed in $1 \mathrm{X}$ PBS to wash off the O.C.T and then baked at $60^{\circ} \mathrm{C}$ for $30 \mathrm{~min}$. Slides were then post-fixed in fresh $4 \%$ PFA for $1 \mathrm{hr}$ at room temperature (RT). After fixation, the sections were dehydrated in a series of ethanol solutions (5 min each in $50 \%, 70 \%$, and two changes of $100 \%$ ethanol) at RT and left to dry for 5 min at RT. Sections were treated with hydrogen peroxide for $10 \mathrm{~min}$ at RT and washed twice with distilled water. Subsequently, target retrieval was performed by boiling the slides for $5 \mathrm{~min}$ in $1 \mathrm{X}$ Target Retrieval Reagent (ACD), washed in distilled water, immersed in 100\% ethanol, and air-dried for 5 min at RT. A hydrophobic barrier was created around the section using an ImmEdge Pen (ACD, 310018) and completely dried at RT before proceeding to the next step. Sections were then treated with protease III for $5 \mathrm{~min}$ at $40^{\circ} \mathrm{C}$ in the pre-warmed ACD HybEZ II Hybridization System (ACD, 321721) inside the HybEZ Humidity Control Tray $(A C D, 310012)$ and washed twice with distilled water. The Foxf2C2 or Olig2-C3 probes were diluted at 1:50 in DARPP32-C1 probe. The sections were then hybridized with the probes, DARPP-32 and Olig2 or DARPP-32 and Foxf2, at $40^{\circ} \mathrm{C}$ for $2 \mathrm{hr}$ in the HybEZ Oven (ACD), washed twice with 1X wash buffer, and stored overnight at RT in 5x SSC buffer (Thermo Fisher Scientific). The next day, the slides were rinsed twice with wash buffer for 2 min each, followed by the three amplification steps (AMP 1, AMP 2, and AMP 3 at $40^{\circ} \mathrm{C}$ for 30, 30, and 15 min respectively, with two washes with wash buffer after each amplification step). The signal was developed by treating the sections in sequence with the horseradish peroxidase (HRP) reagent corresponding to each channel (e.g., HRP-C1) at $40^{\circ} \mathrm{C}$ for $15 \mathrm{~min}$, followed by the TSA Plus fluorophore 
assigned to the probe channel (Opal 690 for DARP32-C1 probe at 1:2000 dilution and Opal 520 for Foxf2-C or Olig2-C3 probes, prepared at a dilution of 1:1500) at $40^{\circ} \mathrm{C}$ for $30 \mathrm{~min}$, and HRP blocker at $40^{\circ} \mathrm{C}$ for $15 \mathrm{~min}$, again with two wash steps after each of the incubation steps. Finally, the slides were counterstained with DAPI for $30 \mathrm{~s}$, mounted using ProLong Gold mounting medium (Thermo Fisher Scientific) and stored at $4^{\circ} \mathrm{C}$ until ready for imaging. The sections were imaged using a $10 \mathrm{x} /$ 0.3 N.A., 20x/0.8 N.A. or 40x/0.75 N.A. objectives on an Axiolmager Z2 microscope (Carl Zeiss), equipped with a Zeiss Axiocam 503, and operated with Zeiss Zen Blue software (Carl Zeiss). Camera exposure times were set for all three channels (red for Opal 690, blue for DAPI and green for Opal 520) and were identical for all slides within each experiment. ImageJ was used for adjusting the brightness and contrast of the images.

\section{Primary neuronal cultures}

E16.5 embryos were obtained from wild-type (WT) Swiss Webster timed bred females purchased from Charles River. E16.5 striatum was removed from by microdissection in cold Leibovitz's medium (L-15) (Gibco-Invitrogen,11415064) and primary medium spiny neuronal cultures were prepared as described (Cirnaru et al., 2019). Briefly, the tissue was incubated in $\mathrm{Ca}^{2+} / \mathrm{Mg}^{2+}$-free Hanks' balanced salt solution (Sigma, 55021C) for $10 \mathrm{~min}$ at $37^{\circ} \mathrm{C}$. The incubation mixture was replaced with $0.1 \mathrm{mg} / \mathrm{ml}$ papain in Hibernate $\mathrm{E} / \mathrm{Ca}^{2+}$ (BrainBits), incubated for $8 \mathrm{~min}$, and rinsed in Dulbecco's minimum essential medium (Gibco-Invitrogen, 21013024) with $20 \%$ fetal bovine serum (Gibco-Invitrogen, 10438026) and twice in Leibovitz's medium (L-15). The tissue was then suspended in Dulbecco's minimum essential medium with $10 \%$ fetal bovine serum, glucose $(6 \mathrm{mg} / \mathrm{mL})$ (Sigma, G7021), glutamine (1.4 mM) (Gibco- Invitrogen, 25030081) and penicillin/streptomycin (100 U/mL) (Gibco-Invitrogen, 15140122). Cells were triturated through a glass bore pipette and plated onto either Lab Tek eight-well slides (1.25 x105 cells/well) for immunocytochemistry or 24-well plates (1x106 cells/well) for RT-PCR analysis, each coated with polymerized polyornithine $(0.1 \mathrm{mg} / \mathrm{mL}$ in 15 $\mathrm{mM}$ borate buffer, $\mathrm{pH}$ 8.4) and air-dried. One hr later, the medium was replaced with Neurobasal (Gibco-Invitrogen, 21103049), supplemented with B27, (Gibco-Invitrogen, 17504044), GLUTAMAX (Gibco- Invitrogen, 35050061) and penicillin/streptomycin. The medium was changed every 2 days, and the cells were assayed on day in vitro (DIV) 9.

\section{Neuronal adenovirus (ADV) transduction}

ADV-CMV-OLIGO2-mCherry, ADV-CMV-FOXF2- mCherry, ADV-CMV-STAT1-V5, and ADV-CMVEGFP were produced by SignaGen Laboratories using the human cDNA sequence. Viral transduction was performed at DIV5 with a multiplicity of infection (MOI) of 20. The virus was added in fresh medium, and the medium was changed $18 \mathrm{hr}$ later. Cells were harvested or fixed $96 \mathrm{hr}$ after addition of virus.

\section{Mouse neuronal immunocytochemistry}

Cells were fixed in $4 \%$ paraformaldehyde in $0.1 \mathrm{M}$ phosphate buffer, $\mathrm{pH} 7.4$, and immunolabeled with mouse anti-DARPP-32 (1:250, sc-271111, Santa Cruz Biotechnology), rabbit anti-Olig2 (1:500, ab136253, Abcam) or rabbit anti-STAT1 (1:400, 14994S, Cell Signaling Technology) followed by antimouse Alexa 488 (1:400, A-11008, Thermo Fisher Scientific) and anti-rabbit Alexa 594 (1:400, A-11012, Thermo Fisher Scientific). To identify the total number of cells the nuclei were stained with DAPI (4', 6-diamino-2-phenylindole dihydrochloride) (1:10,000, Millipore-Sigma). Images were acquired using Olympus BX61 microscope and analyzed using Fiji software (ImageJ).

\section{Real-time qPCR of cultured mouse neurons}

RNA from DIV9 primary MSNs was extracted with the miRNeasy micro kit (Qiagen), according to the manufacturer's instructions. RNAs (500 ng) were reversed-transcribed using the High Capacity RNAto-cDNA Kit (Applied Biosystems). Real-time qPCR was performed in a Step-One Plus system (Applied Biosystems) using All-in-One qPCR Mix (GeneCopoeia). Quantitative PCR consisted of 40 cycles, $15 \mathrm{~s}$ at $95^{\circ} \mathrm{C}$ and $30 \mathrm{~s}$ at $60^{\circ} \mathrm{C}$ each, followed by dissociation curve analysis. The $\Delta \mathrm{Ct}$ was calculated by subtracting the $\mathrm{Ct}$ for the endogenous control gene GAPDH from the $\mathrm{Ct}$ of the gene of interest. Mouse primer sequences are listed in Table 2. Relative quantification was performed using the $\Delta \Delta \mathrm{Ct}$ method and expressed as a fold-change relative to control by calculating $2-\Delta \Delta \mathrm{Ct}$. 
Table 2. RT-qPCR murine primer sequences.

\begin{tabular}{|c|c|c|}
\hline Gene & Primer forward $5^{\prime}-3^{\prime}$ & Primer reverse $5^{\prime}-3^{\prime}$ \\
\hline GAPDH & AACGACCCCTTCATTGACCT & TGGAAGATGGTGATGGGCTT \\
\hline Ppp1r1b & GAAGAAGAAGACAGCCAGGC & TAGTGTTGCTCTGCCTTCCA \\
\hline Oprm1 & СССТСTATTCTATCGTGTGTGT & AGAAGAGAGGATCCAGTTGCA \\
\hline Foxp2 & AAGCAGCTTGCCTTTGCTAAG & GGATTGAATGTATGTGTGGCTGA \\
\hline Rasgrp1 & GGACCTACCAAGAACTGGAAC & GATCCCAGTAAACCCGTCTG \\
\hline Calb 1 & ACTCTCAAACTAGCCGCTGCA & TCAGCGTCGAAATGAAGCC \\
\hline Rasgrp2 & CTTGGACCAGAACCAGGATG & GTGGCAGTTCACACCACAAG \\
\hline Epha7 & TGCTCCGCTTTGCACACACAGG & TAAGTTCTCAATAATGGACCAGCAC \\
\hline Epha4 & TCGTGGTCATTCTCATTG & TCTCTTCATCTGCTTCTTG \\
\hline Ephna5 & CGATAGAACCAAGATAATACT & TAGAATCAGAGGACTCAG \\
\hline
\end{tabular}

\section{Human-induced pluripotent stem-cell-derived NSC culture}

All work on human iPSCs was approved by the Buck Institute institutional stem cell and the human ethics committee (Approval S1002). The isogenic C116 and HD iPSCs were previously published (An et al., 2012; Naphade et al., 2017; Ring et al., 2015; Voisin et al., 2020; Zhang et al., 2010), were sequenced, karyotyped and were negative for mycoplasma contamination. Human-induced pluripotent stem cells (iPSCs) were differentiated into prepatterned activin A-treated neural stem cells (NSCs) by the following protocol. Briefly, iPSC colonies were detached using $1 \mathrm{mg} / \mathrm{ml}$ collagenase (Type IV, Thermo Fisher Scientific, 17104019) in Gibco KnockOut DMEM/F-12 medium (Thermo Fisher Scientific, 12660012), and the resulting cell clumps were transferred to a $0.1 \%$ agarose (Sigma- Aldrich, A9414) coated low-attachment petri dish in embryonic stem (ES) culture medium Gibco KnockOut DMEM/F12 supplemented with 20\% Gibco KnockOut Serum Replacement (Thermo Fisher Scientific, 10828028), 2.5 mM L-glutamine (Thermo Fisher Scientific, 25030081), 1 X NonEssential Amino Acids (NEAAs) (Thermo Fisher Scientific, 11140050), 15 mM HEPES (Thermo Fisher Scientific, 15630106), 0.1 mM $\beta$-mercaptoethanol (Thermo Fisher Scientific, 31350010), $100 \mathrm{U} / \mathrm{ml}$ penicillin-streptomycin (Thermo Fisher Scientific, 15140122). Every 2 days, 25\% of ES medium was replaced by embryoid body (EB) differentiation medium [DMEM (Corning, 10-013- CV) supplemented with 20\% FBS (Thermo Fisher Scientific, 16000036), 1 X NEAA, 2 mM L- glutamine, 100 U/ $\mathrm{ml}$ penicillin-streptomycin]. At day $8,100 \%$ of the culture medium was EB medium. At day 10, the embryoid bodies were attached to dishes coated with poly-L-ornithine (1:1000 in PBS; SigmaAldrich, P3655) and laminin (1:100 in KnockOut DMEM/F-12; Sigma- Aldrich, L2020), and cultured in neural induction medium [DMEM/F12 supplemented with 1 X N2 (Thermo Fisher Scientific, 17502001), $100 \mathrm{U} / \mathrm{ml}$ penicillin-streptomycin] and $25 \mathrm{ng} / \mathrm{ml} \beta F G F$ (Peprotech, 100-18B) and $25 \mathrm{ng} / \mathrm{ml}$ Activin A (Peprotech, 120-14P). Media change was performed every 2 days. Rosettes were harvested after 7-10 days, plated on poly-L-ornithine- and laminin-coated dishes, and cultured in Neural Proliferation Medium [NPM; Neurobasal medium (Thermo Fisher Scientific, 21103049), B27-supplement 1 X (Thermo Fisher Scientific, 17504001), GlutaMAX 1 X (Thermo Fisher Scientific, 35050061), $10 \mathrm{ng} / \mathrm{ml}$ leukemia inhibitory factor (Peprotech, 300-05), $100 \mathrm{U} / \mathrm{ml}$ penicillin-streptomycin] supplemented with $25 \mathrm{ng} / \mathrm{ml} \beta-F G F$ and $25 \mathrm{ng} / \mathrm{ml}$ activin A. The resulting NSCs were passaged and maintained in this same medium. These prepatterned activin A-treated NSCs were validated by immunofluorescence analysis and labeled positively for putative NSC markers, namely Nestin, SOX1, SOX2, and PAX6.

\section{Adenovirus transduction of human NSCs}

For the ADV transduction experiments human iPSC- derived NSCs were plated at 700,000 cells per well of a six-well plate in $2 \mathrm{ml}$ of NPM supplemented with $25 \mathrm{ng} / \mathrm{ml} \beta F G F$ (Peprotech, 100-18B) and $25 \mathrm{ng} / \mathrm{ml}$ activin A (Peprotech, 120-14P). Two day after plating, cells were transduced at $\mathrm{MOl}$ of 10 with ADV-CMV-FOXF2-mCherry (SignaGen Laboratories, SL100701), ADV-CMV-OLIG2-mCherry (SignaGen Laboratories, SL100756) and ADV-CMV-STAT1-6xHN (SignaGen Laboratories, SL110858) and $\mathrm{MOI}$ of 0.75 with ADV-CMV-EGFP (SignaGen Laboratories, SL100708) in $1 \mathrm{ml}$ of NPM without 
penicillin/streptomycin. Then, the cells were placed on an orbital shaker in $37^{\circ} \mathrm{C}$ for $1 \mathrm{hr}$. A complete media change was performed $24 \mathrm{hr}$ post-transduction. Non-transduced NSCs and NSCs transduced with ADV-EGFP were used as controls. Cells were harvested 4 days after transduction for gene expression and immunolabeling assays. ADV transduction in a human iPSC-derived NSC culture was performed twice, with three replicates each.

\section{Cell immunofluorescence of human NSCs}

Cells were fixed using $4 \%$ paraformaldehyde in $0.1 \mathrm{M}$ phosphate-buffered saline (PBS), pH 7.4 (Corning, 21-040-CV) for $30 \mathrm{~min}$. After three washes in PBS, cells were permeabilized and blocked for 1 hr at RT using $0.1 \%$ Triton X-100 (Thermo Fisher Scientific, 28313) and 4\% donkey serum in PBS. Primary antibodies were added in the presence of blocking buffer overnight at $4^{\circ} \mathrm{C}$. Secondary antibodies (1:500) were added after three PBS washes in blocking buffer at RT for $1 \mathrm{hr}$. The following primary antibodies were used for the immunofluorescence studies: rabbit anti-DARPP-32 (Santa Cruz, sc-11365, 1: 100) and rabbit anti-Opioid Receptor-Mu (Millipore, AB5511, 1:500). The secondary antibodies were donkey anti- rabbit IgG conjugated with Alexa-488 (Invitrogen, A12379) or Alexa-647 (Invitrogen, A22287). Images were acquired using a Biotek Cytation five microscope and were prepared using Fiji software (ImageJ).

\section{Quantitative real-time PCR of human NSCs}

For qRT-PCR analysis of prepatterned activin A- treated human NSCs, total RNA was isolated using the ISOLATE II RNA Mini Kit (Bioline, BIO- 52072). cDNA was prepared from 300 ng of RNA in a total reaction volume of $20 \mu \mathrm{l}$ using the Sensi-FAST cDNA synthesis kit (Bioline, BIO-65053). RT-PCR reactions were set up in a 384-well format using $2 \mathrm{X}$ SensiFAST Probe No-ROX Kit (Bioline, BIO$86005)$ and $1 \mu \mathrm{l}$ of cDNA per reaction in a total volume of $10 \mu \mathrm{l}$. RT-PCR was performed on the Roche LightCycler 480 instrument. Quantitative PCR consisted of 40 cycles, $15 \mathrm{~s}$ at $95^{\circ} \mathrm{C}$ and $30 \mathrm{~s}$ at $60^{\circ} \mathrm{C}$ each, followed by dissociation curve analysis. The $\Delta \mathrm{Ct}$ was calculated by subtracting the $\mathrm{Ct}$ for the endogenous control gene $\beta$-actin from the $\mathrm{Ct}$ of the gene of interest. Human primer sequences are listed in Table 3. Relative quantification was performed using the $\Delta \mathrm{Ct}$ method and is expressed as a fold- change relative to control by calculating $2-\Delta \mathrm{Ct}$.

\section{Generation of RNA-seq libraries}

For RNA-seq, EGFP-positive and -negative cells were sorted into low-binding tubes containing Arcturus PicoPure Extraction buffer. RNA was isolated in accordance with the PicoPure RNA Isolation kit manufacturer's instructions, which included a DNase treatment step. Samples were eluted in RNasefree water and stored at $-80^{\circ} \mathrm{C}$ until preparation of RNA-sequencing libraries using the Takara Clontech Laboratories SMARTer Stranded Total RNA-Seq Pico Kit, according to the manufacturer's instructions. After construction of the RNA-seq libraries, libraries were analyzed on an Agilent High Sensitivity D1000 TapeStation, and quantification of the libraries was performed using the KAPA Library Quantification Kit.

Table 3. qRT-PCR human primer sequences.

\begin{tabular}{|c|c|c|c|}
\hline Gene & Primer forward $5^{\prime}-3^{\prime}$ & Primer reverse $5^{\prime}-3^{\prime}$ & Universal probe \\
\hline PPP1R1b & CACACCACCTTCGCTGAAA & GAAGCTCCCCCAGCTCAT & 82 \\
\hline OPRM1 & AGAAACAGCAGGAGCTGTGG & ACCGAGACTTTTCGGGTTC & 30 \\
\hline$B C L 11 b$ & CCCAGAGGGAGCTCATCAC & TTTGACACTGGCCACAGGT & 45 \\
\hline CALB1 & CACAGCCTCACAGTTTTTCG & ССТTTCСТTCCAGGTAACCA & 36 \\
\hline GAD1 & ATGGTGATGGGATATTTTCTCC & GCCATGCCCTTTGTCTTAAC & 46 \\
\hline TUJ1 & GCAACTACGTGGGCGACT & CGAGGCACGTACTTGTGAGA & 78 \\
\hline RASPGRP1 & GAGCCAAAGATCTGCTCCAT & GGTCCGATCCTTACTCTCCTC & 71 \\
\hline RASPGR2 & TGAGCCACAGCTCCATCTC & CCGTCACTAGTTCCGTGAGAC & 75 \\
\hline EPHA4 & AGCAGCCACTCAGGCAAC & ACGAAAATAGGGCGAAATAGAA & 51 \\
\hline ACTB & CCAACCGCGAGAAGATGA & CCAGAGGCGTACAGGGATAG & 64 \\
\hline
\end{tabular}




\section{RNA-seq}

RNA-seq was carried out at New York University using Illumina HiSeq 4000 Paired-End 150 Cycle Lane from purified RNA PicoPure RNA Isolation Kit KIT0204 Arcturus (ThermoScientific) and SMARTer Stranded Total RNA-Seq Kit - Pico Input Mammalian (250 pg-10 ng RNA) (635005, Clontech). The low-quality base (quality score lower than 20 ), as well as the adapters of the raw reads from the sequencing experiments, was removed using Trim Galore! (https://www.bioinformatics.babraham.ac. uk/projects/trim_galore/). External and internal rRNA contamination was filtered through SortMeRNA 2.1b (Kopylova et al., 2012). Then the filtered raw reads were then mapped to the Genome Reference Consortium Mouse Build 38 striosome release 6 (GRCm38.p6) assembly by GENCODE using STAR 2.7.2b (Dobin et al., 2013). The counts of reads mapped to known genes were summarized by featureCounts, using GENECODE release M22 annotation (GSE143276). The data discussed in this publication have been deposited in NCBI's Gene Expression Omnibus GEO Series accession number, GSE143276. Next, R Bioconductor package DESeq2 (Love et al., 2014) was used to normalize raw read counts logarithmically and perform differential expression analysis. Differentially expressed genes were based on an arbitrary cutoff of adjusted p-value less than 0.01 (Figure 2-source data 1). We found the regulation pattern of a gene with the same EGFP status is more likely to be the same across replicates, whereas it is more likely to be different when the EGFP status is different between replicates with the exception of Xist. Xist is a gene highly expressed in females only. The regulation pattern of Xist is consistent with gender differences of the samples confirming the identity of each sample (Figure 2e).

\section{Terminology enrichment analysis and pathway enrichment analysis}

Enrichment analysis was performed on gene clusters in specific databases to determine if a specific biological annotation could be considered as significantly represented under the experiment result. Both terminology enrichment analysis and pathway enrichment analysis were conducted by clusterProfiler (Yu et al., 2012), a Bioconductor package. In our analysis, biological process (BP), molecular function (MF), and cellular component (CC) terms in gene ontology (GO) (The Gene Ontology Consortium, 2017), as well as pathway annotations derived from Kyoto Encyclopedia of Genes and Genomes (KEGG), were chosen to identify predominant biological processes of the differentially expressed gene clusters and differentially expressed transcription factor clusters involved in the development of the striosome neurons. We conducted both analyses on the differentially expressed gene clusters with the arbitrary cutoff of adjusted p-value less than 0.01 and the absolute Log2 foldchange greater than 0,1 , and 2 , respectively, and we conducted both analyses on the differentially expressed transcription factor clusters with the arbitrary cutoff of adjusted p-value less than 0.01 and the absolute Log2 fold- change greater than 0 and 1, respectively (Figure 2-source data 1).

\section{TF enrichment analysis and co-expressor enrichment analysis}

Both TF enrichment analysis and co-expressor enrichment analysis were conducted by Enrichr (Kuleshov et al., 2016), a comprehensive online tool for doing enrichment analysis with a variety of biologically meaningful gene set libraries (Figure 2-source data 1). In our analysis, ChEA (Lachmann et al., 2010) and ENCODE (Frankish et al., 2019) databases were chosen to identify the significant upstream TFs regulating genes and other TFs differentially expressed in striosome cells and matrix cells, respectively, and the ARCHS4 database was chosen to identify the significant coexpressors of those differentially expressed genes and transcription factors. An arbitrary cutoff of adjusted $p$-value less than 0.01 and the absolute log2 fold-changes greater than 0 and 1 were chosen (Figure 2-source data 1).

\section{GeneMANIA gene regulatory network analysis}

GeneMANIA (Warde-Farley et al., 2010) is an online tool using published and computational predicted functional interaction data among proteins and genes to extend and annotate the submitted gene list by their interactive biological pathways and visualize its inferred interaction network accordingly. We used GeneMANIA to conduct the interaction network inference analysis to TFs enriched in either the striosome or matrix compartments with the arbitrary cutoff of adjusted p-value less than 0.01 and the absolute log2 fold-change greater than 1 . 


\section{Gene regulatory network inference through data curation}

A gene regulatory network links TFs to their target genes and represents a map of transcriptional regulation. We used all the TFs and their target gene data curated by ORegAnno (Lesurf et al., 2016) to build the network. To simplify the network, we only chose the compartmental differentially expressed TFs that are high on the hierarchy. In other words, only the differentially expressed TFs that served as a regulator of other differentially expressed TFs were chosen as the candidates of a gene regulatory network.

\section{Gene set enrichment analysis}

GO (Subramanian et alo, 2005) was performed using ranked list of differential gene expression with parameters set to 2000 gene-set permutations and gene-set size between 15 and 200. The genesets included for the GSEA analyses were obtained from Gene Ontology (GO) database (GOBP_AllPathways), updated September 01, 2019 (http://download.baderlab.org/EM_Genesets/). An enrichment map (version 3.2.1 of Enrichment Map software Merico et al., 2010) was generated using Cytoscape 3.7.2 using significantly enriched gene-sets with an FDR $<0.05$. Similarity between genesets was filtered by Jaccard plus overlap combined coefficient (0.375). The resulting enrichment map was further annotated using the AutoAnnotate Cytoscape App.

\section{Data processing}

The preprocessing of ATAC-seq data involved the following steps:

\section{Alignment}

Sequencing reads were provided by the sequencing center demuxed and with adaptors trimmed. Reads from each sample were aligned on GRCh38-mm10 reference genome using the STAR aligner (Dobin et al., 2013) (v2.5.0) with the following parameters:

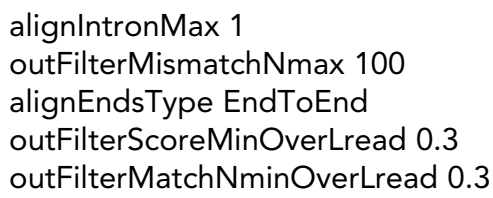

This produced a coordinate-sorted BAM file of mapped paired-end reads for each sample. We excluded reads that: (1) mapped to more than one locus using SAMtools (Li et alo, 2009), (2) were duplicated using PICARD (v2.2.4; http://broadinstitute.github.io/picard; Picard, 2016), and (3) mapped to the mitochondrial genome.

\section{Quality-control (OC) metrics}

The following quality-control metrics were calculated for each sample: (1) total number of initial reads, (2) number of uniquely mapped reads, (3) fraction of reads that were uniquely mapped and additional metrics from the STAR aligner, (4) Picard duplication and insert metrics, and (5) normalized strand cross- correlation coefficient (NSC) and relative strand cross-correlation coefficient (RSC), which are metrics that use cross-correlation of stranded read density profiles to measure enrichment independently of peak calling. Figure 4-source data 1 describes the main $\mathrm{QC}$ metrics. The bigWig tracks for each sample were manually inspected. None of the libraries failed $\mathrm{OC}$ and visual inspection and eight libraries were subjected to further analysis.

\section{Selection and further processing of samples meeting quality control}

We subsequently subsampled samples to a uniform depth of 10 million paired-end reads and merged the BAM-files of samples from the same cell type. We called peaks using the Model-based Analysis of ChIP-Seq (MACS) (Zhang et al., 2008) v2.1 (https://github.com/macs3-project/MACS; Liu, 2015). It models the shift size of tags and models local biases in sequencability and mapability through a dynamic Poisson background model. We used the following parameters:

$$
\begin{aligned}
& \text {-keep-dup all } \\
& \text {-shift -100 } \\
& \text {-extsize } 200
\end{aligned}
$$


-nomodel

We created a joint set of peaks requiring each peak to be called in at least one of the merged BAM-files. That is, if a peak was identified in just one or more samples it was included in the consensus set of peaks. If two or more peaks partially overlapped, the consensus peak was the union of bases covered by the partially overlapping peaks. After removing peaks overlapping the blacklisted genomic regions, 69,229 peaks remained. We subsequently quantified read counts of all the individual non-merged samples within these peaks, again, using the feature counts function in RSubread (Liao et al., 2014) (v.1.15.0). We counted fragments (defined from paired-end reads), instead of individual reads, that overlapped with the final consensus set of peaks. This resulted in a sample by peak matrix of read counts, obtained using the following parameters:

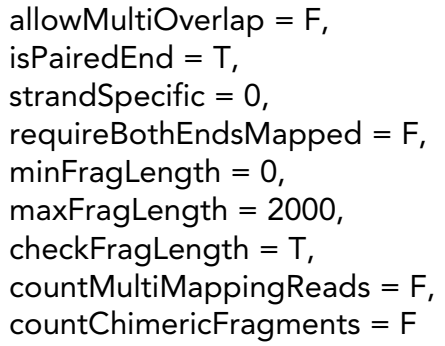

\section{Differential analysis of chromatin accessibility}

To identify genomic regions with significant regional differences in chromatin structure among the two cell types, we performed a statistical analysis of chromatin accessibility. Here, chromatin accessibility was assessed by how many ATAC-seq reads overlap a given OCR: the higher the read count, the more open the chromatin is at a given OCR. For this, we performed the following steps:

\section{Read counts}

As a starting point, we used the sample-by-OCR read count matrix described in the previous section (eight samples by 69,229 OCRs). From here, we subsequently removed nine OCRs using a filtering of 0.5 CPM in at least $50 \%$ of the samples, resulting in our final sample-by-OCR read count matrix (eight samples by 69,220 OCRs). Next, we normalized the read counts using the trimmed mean of M-values (TMM) method (Robinson et al., 2010).

\section{Covariate exploration}

To explore factors affecting the observed read counts, we examined several biological and technical sample-level variables. For these covariates (e.g. number of peaks called in the sample, chrM metrics, RSC and NSC, and Picard insert metrics), we normalized to the median of the cell. We next assessed the correlation of all the covariates with the chromatin accessibility values in the normalized read count matrix to determine which of these variables should be candidates for inclusion as covariates in the differential analysis. We did this using a principal component analysis of the normalized read count matrix and by examining which variables were significantly correlated with the high-variance components (explaining $>1 \%$ of the variance) of the data. We did not identify any significant association even when we used a lenient false discovery rate threshold of 0.2 .

\section{Differential analysis}

We used the edgeR package (Robinson et al., 2010) to model the normalized read counts by negative binomial (NB) distributions. The estimateDisp function was used to estimate an abundancedependent trend for the NB dispersions (McCarthy et al., 2012). To normalize for compositional biases, the effective library size for each sample was estimated using the TMM approach as described above. For each open chromatin region, we applied the following model for the effect on chromatin accessibility of each variable on the right-hand side:

chromatin accessibility cell type.

Then, for each OCR, the cell type coefficient was statistically tested for being non- vanishing. A quasi-likelihood (QL) F-test was conducted for each OCR using the glmOLFTest function 
(Lund et al., 2012) from the edgeR package, with robust estimation of the prior degrees of freedom. p-values were then adjusted for multiple hypothesis testing using false discovery rate (FDR) estimation, and the differentially accessible regions of chromatin were determined as those with an estimated FDR below, or at, $5 \%$.

\section{Annotation of OCRs}

We used the gene annotations form the org.Mm.eg.db (version 3.8.2) package for all analyses in this paper. We assigned the closest gene and the genomic context of an ATAC-seq OCR using ChIPSeeker (Dixon et al., 2015). The genomic context was defined as promoter (+/- $3 \mathrm{~Kb}$ of any TSS), 5'UTR, 3'-UTR, exon, intron, distal intergenic and downstream. TF binding motif analysis of ATAC-seq data was performed using HOMER suit function findMotifsGenome.pl tool. Differential footprinting analysis was performed using TOBIAS (https://doi.org/10.1101/869560) using TF motifs from Jaspar database (doi: 10.1093/nar/gkx1126).

\section{Acknowledgements}

This research was supported by the National Institute of Neurological Disorders and Stroke Grant R01-NS-100529 and the Collaborative Center for X-linked Dystonia Parkinsonism (to LME and MEE). The Taube HD Stem Cell Consortium also provided support (LME) as well as NLM fellowship grant T15LM007442 (HB). A postdoctoral fellowship was provided to KTT from the Collaborative Center for X-linked Dystonia Parkinsonism.

\section{Additional information}

Funding

Funder

\section{Grant reference number}

National Institute of Neurolo- R01-NS-100529 gical Disorders and Stroke

\section{Author}

Maria-Daniela Cirnaru

Sicheng Song

Kizito-Tshitoko Tshilenge

Sean D Mooney

Lisa M Ellerby

Michelle E Ehrlich

Collaborative Center for X--

Linked Dystonia Parkinsonism

at Massachusetts General

Hospital

\begin{tabular}{|c|c|c|}
\hline NLM & T15LM007442 & Houda Benlhabib \\
\hline $\begin{array}{l}\text { The Taube Family Program in } \\
\text { Regenerative Medicine Gen- } \\
\text { ome Editing for Huntington's } \\
\text { Disease at Buck Institute for } \\
\text { Research on Aging }\end{array}$ & & Lisa M Ellerby \\
\hline
\end{tabular}

The funders had no role in study design, data collection and interpretation, or the decision to submit the work for publication.

Author contributions

Maria-Daniela Cirnaru, Conceptualization, Data curation, Formal analysis, Supervision, Validation, Investigation, Visualization, Methodology, Writing - original draft; Sicheng Song, Data curation, Software, Formal analysis, Validation, Investigation, Visualization, Methodology; Kizito-Tshitoko Tshilenge, Data curation, Formal analysis, Supervision, Validation, Investigation, Methodology; Chuhyon Corwin, Formal analysis, Investigation; Justyna Mleczko, Validation, Investigation; Carlos Galicia Aguirre, John Fullard, Software, Formal analysis, Validation, Investigation, Visualization, Methodology; Houda Benlhabib, Supervision, Validation, Investigation, Methodology; Jaroslav Bendl, Software, Formal analysis, Validation, Investigation, Methodology; Pasha Apontes, Data curation, Software, Formal analysis, Validation, Visualization; Jordi Creus-Muncunill, Formal analysis, Validation, Investigation, Visualization; Azadeh Reyahi, Ali M Nik, Peter Carlsson, Resources; Panos 
Roussos, Data curation, Software, Formal analysis, Supervision, Validation, Investigation, Visualization, Project administration; Sean D Mooney, Data curation, Software, Formal analysis, Supervision, Validation, Investigation, Methodology; Lisa M Ellerby, Conceptualization, Resources, Data curation, Software, Formal analysis, Supervision, Funding acquisition, Validation, Investigation, Visualization, Methodology, Writing - original draft, Project administration, Writing - review and editing; Michelle E Ehrlich, Conceptualization, Formal analysis, Supervision, Funding acquisition, Investigation, Writing - original draft, Writing - review and editing

\section{Author ORCIDs}

Houda Benlhabib (D) http://orcid.org/0000-0002-7776-1508

Lisa M Ellerby (iD) https://orcid.org/0000-0002-9050-7977

Michelle E Ehrlich (iD https://orcid.org/0000-0001-9397-686X

Ethics

Animal experimentation: Animal procedures were conducted in accordance with the NIH Guidelines for the Care and Use of Experimental Animals and were approved by the Institutional Animal Care and Use Committee of our institutions (LA09-00272, 16-0847 PRYR1).

Decision letter and Author response

Decision letter https://doi.org/10.7554/eLife.65979.sa1

Author response https://doi.org/10.7554/eLife.65979.sa2

\section{Additional files}

Supplementary files

- Source data 1. Differential expression bioinformatics.

- Source data 2. ATAC-seq samples.

- Source data 3. ATAC-seq results.

- Source data 4. Motif analysis.

- Transparent reporting form

Data availability

All the raw and normalized count are in the GEO data depository (accession codes: GEO is GSE143727 for ATAC-seq and GSE143276 for the RNAseq). Figures 2 and 5-9 have associated raw data. All the data will be available a year from the date of the manuscript publication. The analysis was done using free, publicly available software programs and libraries cited within the methods.

The following datasets were generated:

\begin{tabular}{|c|c|c|c|c|}
\hline Author(s) & Year & Dataset title & Dataset URL & Database and Identifier \\
\hline $\begin{array}{l}\text { Cirnaru M, Song S, } \\
\text { Tshilenge K, Corwin } \\
\text { C, Mleczko J, } \\
\text { Aguirre CG, } \\
\text { Benlhabib H, Bendl } \\
\text { J, Apontes P, } \\
\text { Fullard JF, Creus- } \\
\text { Muncuni J, Reyah } \\
\text { A, Nik AM, } \\
\text { Carlsson P, Roussos } \\
\text { P, Mooney SD, } \\
\text { Ellerby LM, Ehrlich } \\
\text { ME }\end{array}$ & 2020 & $\begin{array}{l}\text { Unbiased identification of } \\
\text { novel transcription factors in } \\
\text { striatal compartmentation and } \\
\text { striosome maturation }\end{array}$ & $\begin{array}{l}\text { https://www.ncbi.nlm. } \\
\text { nih.gov/geo/query/acc. } \\
\text { cgi?acc=GSE143727 }\end{array}$ & $\begin{array}{l}\text { NCBI Gene Expression } \\
\text { Omnibus, GSE143727 }\end{array}$ \\
\hline $\begin{array}{l}\text { Cirnaru M, Song S, } \\
\text { Tshilenge K, Corwin } \\
\text { C, Mleczko J, } \\
\text { Aguirre CG, }\end{array}$ & 2020 & $\begin{array}{l}\text { Unbiased identification of } \\
\text { novel transcription factors in } \\
\text { striatal compartmentation and } \\
\text { striosome maturation }\end{array}$ & $\begin{array}{l}\text { https://www.ncbi.nlm. } \\
\text { nih.gov/geo/query/acc. } \\
\text { cgi?acc=GSE143276 }\end{array}$ & $\begin{array}{l}\text { NCBI Gene Expression } \\
\text { Omnibus, GSE143276 }\end{array}$ \\
\hline
\end{tabular}


Benlhabib H, Bendl

$J$, Apontes $\mathrm{P}$.

Fullard JF, Creus-

Muncuni J, Reyah

A, Nik AM,

Carlsson $\mathrm{P}$, Roussos

$P$, Mooney SD

Ellerby LM, Ehrlich

ME

\section{References}

Adil MM, Gaj T, Rao AT, Kulkarni RU, Fuentes CM, Ramadoss GN, Ekman FK, Miller EW, Schaffer DV. 2018. hPSC-Derived striatal cells generated using a scalable 3D hydrogel promote recovery in a Huntington disease mouse model. Stem Cell Reports 10:1481-1491. DOI: https://doi.org/10.1016/j.stemcr.2018.03.007, PMID: 2 9628395

An MC, Zhang N, Scott G, Montoro D, Wittkop T, Mooney S, Melov S, Ellerby LM. 2012. Genetic correction of Huntington's disease phenotypes in induced pluripotent stem cells. Cell Stem Cell 11:253-263. DOI: https:// doi.org/10.1016/j.stem.2012.04.026, PMID: 22748967

Anderson SA, Qiu M, Bulfone A, Eisenstat DD, Meneses J, Pedersen R, Rubenstein JL. 1997. Mutations of the homeobox genes Dlx-1 and Dlx-2 disrupt the striatal subventricular zone and differentiation of late born striatal neurons. Neuron 19:27-37. DOI: https://doi.org/10.1016/S0896-6273(00)80345-1, PMID: 9247261

Anderson AG, Kulkarni A, Harper M, Konopka G. 2020. Single-Cell analysis of Foxp1-Driven mechanisms essential for striatal development. Cell Reports 30:3051-3066. DOI: https://doi.org/10.1016/j.celrep.2020.02. 030, PMID: 32130906

Arber C, Precious SV, Cambray S, Risner-Janiczek JR, Kelly C, Noakes Z, Fjodorova M, Heuer A, Ungless MA, Rodríguez TA, Rosser AE, Dunnett SB, Li M. 2015. Activin A directs striatal projection neuron differentiation of human pluripotent stem cells. Development 142:1375-1386. DOI: https://doi.org/10.1242/dev.117093, PMID: 25804741

Arlotta P, Molyneaux BJ, Jabaudon D, Yoshida Y, Macklis JD. 2008. Ctip2 controls the differentiation of medium spiny neurons and the establishment of the cellular architecture of the striatum. Journal of Neuroscience 28 : 622-632. DOI: https://doi.org/10.1523/JNEUROSCI.2986-07.2008, PMID: 18199763

Bademci G, Abad C, Incesulu A, Elian F, Reyahi A, Diaz-Horta O, Cengiz FB, Sineni CJ, Seyhan S, Atli El, Basmak H, Demir S, Nik AM, Footz T, Guo S, Duman D, Fitoz S, Gurkan H, Blanton SH, Walter MA, et al. 2019. FOXF2 is required for cochlear development in humans and mice. Human Molecular Genetics 28:1286-1297. DOI: https://doi.org/10.1093/hmg/ddy431, PMID: 30561639

Bentsen M, Goymann P, Schultheis H, Klee K, Petrova A, Wiegandt R, Fust A, Preussner J, Kuenne C, Braun T, Kim J, Looso M. 2020. ATAC-seq footprinting unravels kinetics of transcription factor binding during zygotic genome activation. Nature Communications 11:4267. DOI: https://doi.org/10.1038/s41467-020-18035-1, PMID: 32848148

Beste C, Mückschel M, Rosales R, Domingo A, Lee L, Ng A, Klein C, Münchau A. 2018. The basal ganglia striosomes affect the modulation of conflicts by subliminal Information-Evidence from X-Linked dystonia parkinsonism. Cerebral Cortex 28:2243-2252. DOI: https://doi.org/10.1093/cercor/bhx125, PMID: 28505262

Breuer O, Lawhorn C, Miller T, Smith DM, Brown LL. 2005. Functional architecture of the mammalian striatum: mouse vascular and striosome organization and their anatomic relationships. Neuroscience Letters 385:198203. DOI: https://doi.org/10.1016/j.neulet.2005.05.029, PMID: 15970379

Brimblecombe KR, Cragg SJ. 2017. The striosome and matrix compartments of the striatum: a path through the labyrinth from neurochemistry toward function. ACS Chemical Neuroscience 8:235-242. DOI: https://doi.org/ 10.1021/acschemneuro.6b00333, PMID: 27977131

Campbell P, Reep RL, Stoll ML, Ophir AG, Phelps SM. 2009. Conservation and diversity of Foxp2 expression in muroid rodents: functional implications. The Journal of Comparative Neurology 512:84-100. DOI: https://doi. org/10.1002/cne.21881, PMID: 18972576

Cazorla M, Kang UJ, Kellendonk C. 2015. Balancing the basal ganglia circuitry: a possible new role for dopamine D2 receptors in health and disease. Movement Disorders 30:895-903. DOI: https://doi.org/10.1002/mds. 26282, PMID: 26018615

Chakrabarti L, Best TK, Cramer NP, Carney RS, Isaac JT, Galdzicki Z, Haydar TF. 2010. Olig1 and Olig2 triplication causes developmental brain defects in down syndrome. Nature Neuroscience 13:927-934. DOI: https://doi.org/10.1038/nn.2600, PMID: 20639873

Chandwani S, Keilani S, Ortiz-Virumbrales M, Morant A, Bezdecny S, Ehrlich ME. 2013. Induction of DARPP-32 by brain-derived neurotrophic factor in striatal neurons in vitro is modified by histone deacetylase inhibitors and Nab2. PLOS ONE 8:e76842. DOI: https://doi.org/10.1371/journal.pone.0076842, PMID: 24204683

Chen EY, Tan CM, Kou Y, Duan Q, Wang Z, Meirelles GV, Clark NR, Ma'ayan A. 2013. Enrichr: interactive and collaborative HTML5 gene list enrichment analysis tool. BMC Bioinformatics 14:128. DOI: https://doi.org/10. 1186/1471-2105-14-128, PMID: 23586463

Chew LJ, Ming X, McEllin B, Dupree J, Hong E, Catron M, Fauveau M, Nait-Oumesmar B, Gallo V. 2019. Sox17 regulates a program of oligodendrocyte progenitor cell expansion and differentiation during development and repair. Cell Reports 29:3173-3186. DOI: https://doi.org/10.1016/j.celrep.2019.10.121, PMID: 31801081 
Cirnaru MD, Melis C, Fanutza T, Naphade S, Tshilenge KT, Muntean BS, Martemyanov KA, Plotkin JL, Ellerby LM, Ehrlich ME. 2019. Nuclear receptor $\mathrm{Nr}_{4} \mathrm{a}_{1}$ regulates striatal striosome development and dopamine $D_{1}$ Receptor Signaling. Eneuro 6:ENEURO.0305-19.2019. DOI: https://doi.org/10.1523/ENEURO.0305-19.2019, PMID: 31541002

Cooper MA, Kobayashi K, Zhou R. 2009. Ephrin-A5 regulates the formation of the ascending midbrain dopaminergic pathways. Developmental Neurobiology 69:36-46. DOI: https://doi.org/10.1002/dneu.20685, PMID: 19003794

Crittenden JR, Graybiel AM. 2011. Basal ganglia disorders associated with imbalances in the striatal striosome and matrix compartments. Frontiers in Neuroanatomy 5:59. DOI: https://doi.org/10.3389/fnana.2011.00059, PMID: 21941467

Davis MI, Puhl HL. 2011. Nr4a1-eGFP is a marker of striosome-matrix architecture, development and activity in the extended striatum. PLOS ONE 6:e16619. DOl: https://doi.org/10.1371/journal.pone.0016619, PMID: 21305052

Delgoffe GM, Vignali DA. 2013. STAT heterodimers in immunity: a mixed message or a unique signal? Jak-Stat 2:e23060. DOI: https://doi.org/10.4161/jkst.23060, PMID: 24058793

Deriziotis P, Fisher SE. 2017. Speech and language: translating the genome. Trends in Genetics 33:642-656. DOI: https://doi.org/10.1016/j.tig.2017.07.002, PMID: 28781152

Dixon JR, Jung I, Selvaraj S, Shen Y, Antosiewicz-Bourget JE, Lee AY, Ye Z, Kim A, Rajagopal N, Xie W, Diao Y, Liang J, Zhao H, Lobanenkov VV, Ecker JR, Thomson JA, Ren B. 2015. Chromatin architecture reorganization during stem cell differentiation. Nature 518:331-336. DOI: https://doi.org/10.1038/nature14222, PMID: 256 93564

Dobin A, Davis CA, Schlesinger F, Drenkow J, Zaleski C, Jha S, Batut P, Chaisson M, Gingeras TR. 2013. STAR: ultrafast universal RNA-seq aligner. Bioinformatics 29:15-21. DOI: https://doi.org/10.1093/bioinformatics/ bts635, PMID: 23104886

Dufour A, Seibt J, Passante L, Depaepe V, Ciossek T, Frisén J, Kullander K, Flanagan JG, Polleux F, Vanderhaeghen P. 2003. Area specificity and topography of thalamocortical projections are controlled by ephrin/Eph genes. Neuron 39:453-465. DOI: https://doi.org/10.1016/S0896-6273(03)00440-9, PMID: 12895420

Ehrman LA, Mu X, Waclaw RR, Yoshida Y, Vorhees CV, Klein WH, Campbell K. 2013. The LIM homeobox gene Isl1 is required for the correct development of the striatonigral pathway in the mouse. PNAS 110:E4026E4035. DOI: https://doi.org/10.1073/pnas.1308275110, PMID: 24082127

Evans AE, Kelly CM, Precious SV, Rosser AE. 2012. Molecular regulation of striatal development: a review. Anatomy Research International 2012:1-14. DOI: https://doi.org/10.1155/2012/106529

Feuk L, Kalervo A, Lipsanen-Nyman M, Skaug J, Nakabayashi K, Finucane B, Hartung D, Innes M, Kerem B, Nowaczyk MJ, Rivlin J, Roberts W, Senman L, Summers A, Szatmari P, Wong V, Vincent JB, Zeesman S, Osborne LR, Cardy JO, et al. 2006. Absence of a paternally inherited FOXP2 gene in developmental verbal dyspraxia. The American Journal of Human Genetics 79:965-972. DOI: https://doi.org/10.1086/508902, PMID: 17033973

Fishell G, van der Kooy D. 1987. Pattern formation in the striatum: developmental changes in the distribution of striatonigral neurons. The Journal of Neuroscience 7:1969-1978. DOI: https://doi.org/10.1523/JNEUROSCI.0707-01969.1987, PMID: 2886562

Fishell G, van der Kooy D. 1989. Pattern formation in the striatum: developmental changes in the distribution of striatonigral projections. Developmental Brain Research 45:239-255. DOI: https://doi.org/10.1016/0165-3806 (89)90042-4, PMID: 2713982

Fjodorova M, Louessard M, Li Z, De La Fuente DC, Dyke E, Brooks SP, Perrier AL, Li M. 2019. CTIP2-Regulated reduction in PKA-Dependent DARPP32 phosphorylation in human medium spiny neurons: implications for Huntington disease. Stem Cell Reports 13:448-457. DOI: https://doi.org/10.1016/j.stemcr.2019.07.015, PMID: 31447328

Frankish A, Diekhans M, Ferreira AM, Johnson R, Jungreis I, Loveland J, Mudge JM, Sisu C, Wright J, Armstrong J, Barnes I, Berry A, Bignell A, Carbonell Sala S, Chrast J, Cunningham F, Di Domenico T, Donaldson S, Fiddes IT, García Girón C, et al. 2019. GENCODE reference annotation for the human and mouse genomes. Nucleic Acids Research 47:D766-D773. DOI: https://doi.org/10.1093/nar/gky955, PMID: 30357393

Fujiyama F, Unzai T, Karube F. 2019. Thalamostriatal projections and striosome-matrix compartments. Neurochemistry International 125:67-73. DOI: https://doi.org/10.1016/j. neuint.2019.01.024, PMID: 30710558 Fullard JF, Hauberg ME, Bendl J, Egervari G, Cirnaru MD, Reach SM, Motl J, Ehrlich ME, Hurd YL, Roussos P. 2018. An atlas of chromatin accessibility in the adult human brain. Genome Research 28:1243-1252. DOI: https://doi.org/10.1101/gr.232488.117, PMID: 29945882

Fulp CT, Cho G, Marsh ED, Nasrallah IM, Labosky PA, Golden JA. 2008. Identification of arx transcriptional targets in the developing basal forebrain. Human Molecular Genetics 17:3740-3760. DOI: https://doi.org/10. 1093/hmg/ddn271, PMID: 18799476

Giguère V. 1999. Orphan nuclear receptors: from gene to function. Endocrine Reviews 20:689-725. DOI: https:// doi.org/10.1210/er.20.5.689, PMID: 10529899

Gokce O, Stanley GM, Treutlein B, Neff NF, Camp JG, Malenka RC, Rothwell PE, Fuccillo MV, Südhof TC, Quake SR. 2016. Cellular taxonomy of the mouse striatum as revealed by Single-Cell RNA-Seq. Cell Reports 16:11261137. DOI: https://doi.org/10.1016/j.celrep.2016.06.059, PMID: 27425622

Golas MM. 2018. Human cellular models of medium spiny neuron development and Huntington disease. Life Sciences 209:179-196. DOI: https://doi.org/10.1016/j.lfs.2018.07.030, PMID: 30031060 
Goto S, Lee LV, Munoz EL, Tooyama I, Tamiya G, Makino S, Ando S, Dantes MB, Yamada K, Matsumoto S, Shimazu H, Kuratsu J, Hirano A, Kaji R. 2005. Functional anatomy of the basal ganglia in X-linked recessive dystonia-parkinsonism. Annals of Neurology 58:7-17. DOI: https://doi.org/10.1002/ana.20513, PMID: 159124 96

Graybiel AM. 1984. Correspondence between the dopamine islands and striosomes of the mammalian striatum. Neuroscience 13:1157-1187. DOI: https://doi.org/10.1016/0306-4522(84)90293-8, PMID: 6152035

Haddad-Tóvolli R, Dragano NRV, Ramalho AFS, Velloso LA. 2017. Development and function of the Blood-Brain barrier in the context of metabolic control. Frontiers in Neuroscience 11:224. DOI: https://doi.org/10.3389/ fnins.2017.00224, PMID: 28484368

Hauberg ME, Creus-Muncunill J, Bendl J, Kozlenkov A, Zeng B, Corwin C, Chowdhury S, Kranz H, Hurd YL, Wegner M, Børglum AD, Dracheva S, Ehrlich ME, Fullard JF, Roussos P. 2020. Common schizophrenia risk variants are enriched in open chromatin regions of human glutamatergic neurons. Nature Communications 11: 5581. DOI: https://doi.org/10.1038/s41467-020-19319-2, PMID: 33149216

Hedreen JC, Folstein SE. 1995. Early loss of neostriatal striosome neurons in Huntington's disease. Journal of Neuropathology and Experimental Neurology 54:105-120. DOl: https://doi.org/10.1097/00005072-19950100000013, PMID: 7815073

Heinz S, Benner C, Spann N, Bertolino E, Lin YC, Laslo P, Cheng JX, Murre C, Singh H, Glass CK. 2010. Simple combinations of Lineage-Determining transcription factors prime cis-Regulatory elements required for macrophage and B cell identities. Molecular Cell 38:576-589. DOI: https://doi.org/10.1016/j.molcel.2010.05 004

Ho H, Both M, Siniard A, Sharma S, Notwell JH, Wallace M, Leone DP, Nguyen A, Zhao E, Lee H, Zwilling D, Thompson KR, Braithwaite SP, Huentelman M, Portmann T. 2018. A guide to Single-Cell transcriptomics in adult rodent brain: the medium spiny neuron transcriptome revisited. Frontiers in Cellular Neuroscience 12: 159. DOI: https://doi.org/10.3389/fncel.2018.00159, PMID: 29970990

Hobert O. 2016. Terminal selectors of neuronal identity. Current Topics in Developmental Biology 116:455-475. DOI: https://doi.org/10.1016/bs.ctdb.2015.12.007, PMID: 26970634

Hupe M, Li MX, Kneitz S, Davydova D, Yokota C, Kele J, Hot B, Stenman JM, Gessler M. 2017. Gene expression profiles of brain endothelial cells during embryonic development at bulk and single-cell levels. Science Signaling 10:aag2476. DOI: https://doi.org/10.1126/scisignal.aag2476

Inamura N, Ono K, Takebayashi H, Zalc B, lkenaka K. 2011. Olig2 lineage cells generate GABAergic neurons in the prethalamic nuclei, including the zona incerta, ventral lateral geniculate nucleus and reticular thalamic nucleus. Developmental Neuroscience 33:118-129. DOI: https://doi.org/10.1159/000328974, PMID: 21865661

Ivkovic S, Ehrlich ME. 1999. Expression of the striatal DARPP-32/ARPP-21 phenotype in GABAergic neurons requires neurotrophins in vivo and in vitro. The Journal of Neuroscience 19:5409-5419. DOI: https://doi.org/10. 1523/JNEUROSCI.19-13-05409.1999, PMID: 10377350

Jakovcevski I, Zecevic N. 2005. Olig transcription factors are expressed in Oligodendrocyte and neuronal cells in human fetal CNS. Journal of Neuroscience 25:10064-10073. DOI: https://doi.org/10.1523/JNEUROSCI.232405.2005, PMID: 16267213

Janis LS, Cassidy RM, Kromer LF. 1999. Ephrin-A binding and EphA receptor expression delineate the matrix compartment of the striatum. The Journal of Neuroscience 19:4962-4971. DOI: https://doi.org/10.1523/ JNEUROSCI.19-12-04962.1999, PMID: 10366629

Keeler JF, Pretsell DO, Robbins TW. 2014. Functional implications of dopamine D1 vs. D2 receptors: a 'prepare and select' model of the striatal direct vs. indirect pathways. Neuroscience 282:156-175. DOI: https://doi.org/ 10.1016/j.neuroscience.2014.07.021, PMID: 25062777

Kemp PJ, Rushton DJ, Yarova PL, Schnell C, Geater C, Hancock JM, Wieland A, Hughes A, Badder L, Cope E, Riccardi D, Randall AD, Brown JT, Allen ND, Telezhkin V. 2016. Improving and accelerating the differentiation and functional maturation of human stem cell-derived neurons: role of extracellular calcium and GABA. The Journal of Physiology 594:6583-6594. DOI: https://doi.org/10.1113/JP270655, PMID: 27616476

Kim HM, Hwang DH, Choi JY, Park CH, Suh-Kim H, Kim SU, Kim BG. 2011. Differential and cooperative actions of Olig1 and Olig2 transcription factors on immature proliferating cells after contusive spinal cord injury. Glia 59:1094-1106. DOI: https://doi.org/10.1002/glia.21182, PMID: 21538562

Kim YJ, Ibrahim LA, Wang SZ, Yuan W, Evgrafov OV, Knowles JA, Wang K, Tao HW, Zhang LI. 2016. EphA7 regulates spiral ganglion innervation of cochlear hair cells. Developmental Neurobiology 76:452-469. DOI: https://doi.org/10.1002/dneu.22326, PMID: 26178595

Konopka G, Bomar JM, Winden K, Coppola G, Jonsson ZO, Gao F, Peng S, Preuss TM, Wohlschlegel JA, Geschwind DH. 2009. Human-specific transcriptional regulation of CNS development genes by FOXP2. Nature 462:213-217. DOI: https://doi.org/10.1038/nature08549, PMID: 19907493

Kopylova E, Noé L, Touzet H. 2012. SortMeRNA: fast and accurate filtering of ribosomal RNAs in Metatranscriptomic data. Bioinformatics 28:3211-3217. DOI: https://doi.org/10.1093/bioinformatics/bts611, PMID: 23071270

Kuleshov MV, Jones MR, Rouillard AD, Fernandez NF, Duan Q, Wang Z, Koplev S, Jenkins SL, Jagodnik KM, Lachmann A, McDermott MG, Monteiro CD, Gundersen GW, Ma'ayan A. 2016. Enrichr: a comprehensive gene set enrichment analysis web server 2016 update. Nucleic Acids Research 44:W90-W97. DOI: https://doi.org/ 10.1093/nar/gkw377, PMID: 27141961

Kuo HY, Liu FC. 2017. Valproic acid induces aberrant development of striatal compartments and corticostriatal pathways in a mouse model of autism spectrum disorder. The FASEB Journal 31:4458-4471. DOI: https://doi. org/10.1096/fj.201700054R, PMID: 28687613 
Kuo HY, Liu FC. 2020. Pathological alterations in striatal compartments in the human brain of autism spectrum disorder. Molecular Brain 13:83. DOI: https://doi.org/10.1186/s13041-020-00624-2, PMID: 32460809

Lachmann A, Xu H, Krishnan J, Berger SI, Mazloom AR, Ma'ayan A. 2010. ChEA: transcription factor regulation inferred from integrating genome-wide ChIP-X experiments. Bioinformatics 26:2438-2444. DOI: https://doi. org/10.1093/bioinformatics/btq466, PMID: 20709693

Lai CS, Fisher SE, Hurst JA, Vargha-Khadem F, Monaco AP. 2001. A forkhead-domain gene is mutated in a severe speech and language disorder. Nature 413:519-523. DOI: https://doi.org/10.1038/35097076, PMID: 11586359

Lawhorn C, Smith DM, Brown LL. 2008. Striosome-matrix pathology and motor deficits in the YAC128 mouse model of Huntington's disease. Neurobiology of Disease 32:471-478. DOI: https://doi.org/10.1016/j.nbd.2008. 08.006, PMID: 18809498

Lee H, Park E, Kim Y, Park S. 2013. EphrinA5-EphA7 complex induces apoptotic cell death via TNFR1. Molecules and Cells 35:450-455. DOI: https://doi.org/10.1007/s10059-013-0072-3, PMID: 23657875

Lesurf R, Cotto KC, Wang G, Griffith M, Kasaian K, Jones SJM, Montgomery SB, Griffith OL, The Open Regulatory Annotation Consortium. 2016. ORegAnno 3.0: a community-driven resource for curated regulatory annotation. Nucleic Acids Research 44:D126-D132. DOI: https://doi.org/10.1093/nar/gkv1203

Li H, Handsaker B, Wysoker A, Fennell T, Ruan J, Homer N, Marth G, Abecasis G, Durbin R. 2009. The sequence alignment/Map format and SAMtools. Bioinformatics 25:2078-2079. DOI: https://doi.org/10.1093/ bioinformatics/btp352, PMID: 19505943

Li Y, Wang X, Yao L. 2015. Directional migration and transcriptional analysis of oligodendrocyte precursors subjected to stimulation of electrical signal. American Journal of Physiology-Cell Physiology 309:C532-C540. DOI: https://doi.org/10.1152/ajpcell.00175.2015, PMID: 26269459

Li S, Kumar T P, Joshee S, Kirschstein T, Subburaju S, Khalili JS, Kloepper J, Du C, Elkhal A, Szabó G, Jain RK, Köhling R, Vasudevan A. 2018. Endothelial cell-derived GABA signaling modulates neuronal migration and postnatal behavior. Cell Research 28:221-248. DOI: https://doi.org/10.1038/cr.2017.135, PMID: 29086765

Liao Y, Smyth GK, Shi W. 2014. featureCounts: an efficient general purpose program for assigning sequence reads to genomic features. Bioinformatics 30:923-930. DOI: https://doi.org/10.1093/bioinformatics/btt656, PMID: 24227677

Liu D, Jia H, Holmes DI, Stannard A, Zachary I. 2003. Vascular endothelial growth factor-regulated gene expression in endothelial cells: kdr-mediated induction of Egr3 and the related nuclear receptors Nur77, Nurr1, and Nor1. Arteriosclerosis, Thrombosis, and Vascular Biology 23:2002-2007. DOI: https://doi.org/10.1161/01. ATV.0000098644.03153.6F, PMID: 14525795

Liu T. 2015. MACS: Model-based Analysis for ChIP-Seq. Github. 2.1. https://github.com/macs3-project/MACS

Liu FC, Graybiel AM. 1992. Transient calbindin-D28k-positive systems in the telencephalon: ganglionic eminence, developing striatum and cerebral cortex. The Journal of Neuroscience 12:674-690. DOI: https://doi.org/10. 1523/JNEUROSCI.12-02-00674.1992, PMID: 1740695

Lobo MK, Karsten SL, Gray M, Geschwind DH, Yang XW. 2006. FACS-array profiling of striatal projection neuron subtypes in juvenile and adult mouse brains. Nature Neuroscience 9:443-452. DOI: https://doi.org/10.1038/ nn1654, PMID: 16491081

Long JE, Swan C, Liang WS, Cobos I, Potter GB, Rubenstein JL. 2009. Dlx1\&2 and Mash1 transcription factors control striatal patterning and differentiation through parallel and overlapping pathways. The Journal of Comparative Neurology 512:556-572. DOI: https://doi.org/10.1002/cne.21854, PMID: 19030180

Love MI, Huber W, Anders S. 2014. Moderated estimation of fold change and dispersion for RNA-seq data with DESeq2. Genome Biology 15:550. DOI: https://doi.org/10.1186/s13059-014-0550-8, PMID: 25516281

Lund SP, Nettleton D, McCarthy DJ, Smyth GK. 2012. Detecting differential expression in RNA-sequence data using Quasi-likelihood with shrunken dispersion estimates. Statistical Applications in Genetics and Molecular Biology 11:1826. DOI: https://doi.org/10.1515/1544-6115.1826

MacDermot KD, Bonora E, Sykes N, Coupe AM, Lai CS, Vernes SC, Vargha-Khadem F, McKenzie F, Smith RL, Monaco AP, Fisher SE. 2005. Identification of FOXP2 truncation as a novel cause of developmental speech and language deficits. The American Journal of Human Genetics 76:1074-1080. DOI: https://doi.org/10.1086/ 430841, PMID: 15877281

Marin O, Anderson SA, Rubenstein JL. 2000. Origin and molecular specification of striatal interneurons. The Journal of Neuroscience 20:6063-6076. DOI: https://doi.org/10.1523/JNEUROSCI.20-16-06063.2000, PMID: 10 934256

Märtin A, Calvigioni D, Tzortzi O, Fuzik J, Wärnberg E, Meletis K. 2019. A spatiomolecular map of the striatum. Cell Reports 29:4320-4333. DOI: https://doi.org/10.1016/j.celrep.2019.11.096, PMID: 31875543

Martín-lbáñez R, Crespo E, Esgleas M, Urban N, Wang B, Waclaw R, Georgopoulos K, Martínez S, Campbell K, Vicario-Abejón C, Alberch J, Chan S, Kastner P, Rubenstein JL, Canals JM. 2012. Helios transcription factor expression depends on Gsx2 and Dlx1\&2 function in developing striatal matrix neurons. Stem Cells and Development 21:2239-2251. DOI: https://doi.org/10.1089/scd.2011.0607, PMID: 22142223

Martín-lbáñez R, Pardo M, Giralt A, Miguez A, Guardia I, Marion-Poll L, Herranz C, Esgleas M, Garcia-Díaz Barriga G, Edel MJ, Vicario-Abejón C, Alberch J, Girault JA, Chan S, Kastner P, Canals JM. 2017. Helios expression coordinates the development of a subset of striatopallidal medium spiny neurons. Development 144:1566-1577. DOI: https://doi.org/10.1242/dev.138248, PMID: 28289129

Mason HA, Rakowiecki SM, Raftopoulou M, Nery S, Huang Y, Gridley T, Fishell G. 2005. Notch signaling coordinates the patterning of striatal compartments. Development 132:4247-4258. DOI: https://doi.org/10. 1242/dev.02008, PMID: 16120638 
Matsushima A, Graybiel AM. 2020. Combinatorial developmental controls on striatonigral circuits. Cell Reports 31:107778. DOI: https://doi.org/10.1016/j.celrep.2020.107778, PMID: 32553154

McCarthy DJ, Chen Y, Smyth GK. 2012. Differential expression analysis of multifactor RNA-Seq experiments with respect to biological variation. Nucleic Acids Research 40:4288-4297. DOI: https://doi.org/10.1093/nar/ gks042, PMID: 22287627

Menezes JR, Luskin MB. 1994. Expression of neuron-specific tubulin defines a novel population in the proliferative layers of the developing telencephalon. The Journal of Neuroscience 14:5399-5416. DOI: https:// doi.org/10.1523/JNEUROSCI.14-09-05399.1994, PMID: 8083744

Merico D, Isserlin R, Stueker O, Emili A, Bader GD. 2010. Enrichment map: a network-based method for geneset enrichment visualization and interpretation. PLOS ONE 5:e13984. DOI: https://doi.org/10.1371/journal. pone.0013984, PMID: 21085593

Miyamoto Y, Katayama S, Shigematsu N, Nishi A, Fukuda T. 2018. Striosome-based map of the mouse striatum that is conformable to both cortical afferent topography and uneven distributions of dopamine D1 and D2 receptor-expressing cells. Brain Structure and Function 223:4275-4291. DOI: https://doi.org/10.1007/s00429018-1749-3, PMID: 30203304

Muñoz-Manchado AB, Bengtsson Gonzales C, Zeisel A, Munguba H, Bekkouche B, Skene NG, Lönnerberg P, Ryge J, Harris KD, Linnarsson S, Hjerling-Leffler J. 2018. Diversity of interneurons in the dorsal striatum revealed by Single-Cell RNA sequencing and PatchSeq. Cell Reports 24:2179-2190. DOI: https://doi.org/10. 1016/j.celrep.2018.07.053, PMID: 30134177

Naphade S, Embusch A, Madushani KL, Ring KL, Ellerby LM. 2017. Altered expression of matrix metalloproteinases and their endogenous inhibitors in a human isogenic stem cell model of Huntington's Disease. Frontiers in Neuroscience 11:736. DOI: https://doi.org/10.3389/fnins.2017.00736, PMID: 29459817

Ono K, Clavairoly A, Nomura T, Gotoh H, Uno A, Armant O, Takebayashi H, Zhang Q, Shimamura K, Itohara S, Parras CM, Ikenaka K. 2014. Development of the prethalamus is crucial for thalamocortical projection formation and is regulated by Olig2. Development 141:2075-2084. DOI: https://doi.org/10.1242/dev.097790, PMID: 24 803655

Ormestad M, Astorga J, Landgren H, Wang T, Johansson BR, Miura N, Carlsson P. 2006. Foxf1 and Foxf2 control murine gut development by limiting mesenchymal wnt signaling and promoting extracellular matrix production. Development 133:833-843. DOI: https://doi.org/10.1242/dev.02252, PMID: 16439479

Ortiz C, Navarro JF, Jurek A, Märtin A, Lundeberg J, Meletis K. 2020. Molecular atlas of the adult mouse brain. Science Advances 6:eabb3446. DOI: https://doi.org/10.1126/sciadv.abb3446, PMID: 32637622

Paredes MF, James D, Gil-Perotin S, Kim H, Cotter JA, Ng C, Sandoval K, Rowitch DH, Xu D, McQuillen PS, Garcia-Verdugo JM, Huang EJ, Alvarez-Buylla A. 2016. Extensive migration of young neurons into the infant human frontal lobe. Science 354:aaf7073. DOI: https://doi.org/10.1126/science.aaf7073, PMID: 27846470

Passante L, Gaspard N, Degraeve M, Frisén J, Kullander K, De Maertelaer V, Vanderhaeghen P. 2008. Temporal regulation of ephrin/Eph signalling is required for the spatial patterning of the mammalian striatum. Development 135:3281-3290. DOI: https://doi.org/10.1242/dev.024778, PMID: 18755772

Petryniak MA, Potter GB, Rowitch DH, Rubenstein JL. 2007. Dlx1 and Dlx2 control neuronal versus oligodendroglial cell fate acquisition in the developing forebrain. Neuron 55:417-433. DOI: https://doi.org/10. 1016/j.neuron.2007.06.036, PMID: 17678855

Picard. 2016. Broadinstitute/Picard Toolkit. Github. 2.2.4. https://github.com/broadinstitute/picard

Prager EM, Dorman DB, Hobel ZB, Malgady JM, Blackwell KT, Plotkin JL. 2020. Dopamine oppositely modulates state transitions in Striosome and matrix direct pathway striatal spiny neurons. Neuron 108:1091-1102. DOI: https://doi.org/10.1016/j.neuron.2020.09.028, PMID: 33080228

Precious SV, Kelly CM, Reddington AE, Vinh NN, Stickland RC, Pekarik V, Scherf C, Jeyasingham R, Glasbey J, Holeiter M, Jones L, Taylor MV, Rosser AE. 2016. FoxP1 marks medium spiny neurons from precursors to maturity and is required for their differentiation. Experimental Neurology 282:9-18. DOI: https://doi.org/10. 1016/j.expneurol.2016.05.002, PMID: 27154297

Puelles L, Kuwana E, Puelles E, Bulfone A, Shimamura K, Keleher J, Smiga S, Rubenstein JL. 2000. Pallial and subpallial derivatives in the embryonic chick and mouse telencephalon, traced by the expression of the genes Dlx-2, Emx-1, Nkx-2.1, Pax-6, and Tbr-1. The Journal of Comparative Neurology 424:409-438. DOI: https://doi. org/10.1002/1096-9861(20000828)424:3<409::AID-CNE3>3.0.CO;2-7, PMID: 10906711

Rataj-Baniowska M, Niewiadomska-Cimicka A, Paschaki M, Szyszka-Niagolov M, Carramolino L, Torres M, Dollé

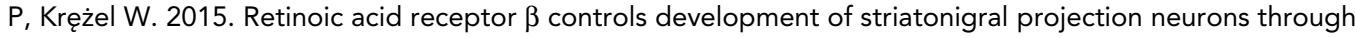
FGF-Dependent and Meis1-Dependent mechanisms. Journal of Neuroscience 35:14467-14475. DOI: https:// doi.org/10.1523/JNEUROSCI.1278-15.2015, PMID: 26511239

Reyahi A, Nik AM, Ghiami M, Gritli-Linde A, Pontén F, Johansson BR, Carlsson P. 2015. Foxf2 is required for brain pericyte differentiation and development and maintenance of the Blood-Brain barrier. Developmental Cell 34:19-32. DOI: https://doi.org/10.1016/j.devcel.2015.05.008, PMID: 26120030

Richner M, Victor MB, Liu Y, Abernathy D, Yoo AS. 2015. MicroRNA-based conversion of human fibroblasts into striatal medium spiny neurons. Nature Protocols 10:1543-1555. DOI: https://doi.org/10.1038/nprot.2015.102, PMID: 26379228

Ring KL, An MC, Zhang N, O'Brien RN, Ramos EM, Gao F, Atwood R, Bailus BJ, Melov S, Mooney SD, Coppola G, Ellerby LM. 2015. Genomic analysis reveals disruption of striatal neuronal development and therapeutic targets in human Huntington's Disease Neural Stem Cells. Stem Cell Reports 5:1023-1038. DOI: https://doi. org/10.1016/j.stemcr.2015.11.005, PMID: 26651603 
Robinson MD, McCarthy DJ, Smyth GK. 2010. edgeR: a bioconductor package for differential expression analysis of digital gene expression data. Bioinformatics 26:139-140. DOI: https://doi.org/10.1093/bioinformatics/ btp616, PMID: 19910308

Saunders A, Macosko EZ, Wysoker A, Goldman M, Krienen FM, de Rivera H, Bien E, Baum M, Bortolin L, Wang S, Goeva A, Nemesh J, Kamitaki N, Brumbaugh S, Kulp D, McCarroll SA. 2018. Molecular diversity and specializations among the cells of the adult mouse brain. Cell 174:1015-1030. DOI: https://doi.org/10.1016/j. cell.2018.07.028, PMID: 30096299

Setoguchi T, Kondo T. 2004. Nuclear export of OLIG2 in neural stem cells is essential for ciliary neurotrophic factor-induced astrocyte differentiation. Journal of Cell Biology 166:963-968. DOI: https://doi.org/10.1083/jcb. 200404104

Smith JB, Klug JR, Ross DL, Howard CD, Hollon NG, Ko VI, Hoffman H, Callaway EM, Gerfen CR, Jin X. 2016. Genetic-Based dissection unveils the inputs and outputs of striatal patch and matrix compartments. Neuron 91: 1069-1084. DOI: https://doi.org/10.1016/j.neuron.2016.07.046, PMID: 27568516

Snyder-Keller A, Tseng KY, Lyng GD, Graber DJ, O’Donnell P. 2008. Afferent influences on striatal development in organotypic cocultures. Synapse 62:487-500. DOI: https://doi.org/10.1002/syn.20518, PMID: 18435420

Stanley G, Gokce O, Malenka RC, Südhof TC, Quake SR. 2020. Continuous and discrete neuron types of the adult murine striatum. Neuron 105:688-699. DOI: https://doi.org/10.1016/j.neuron.2019.11.004, PMID: 31 813651

Subramanian A, Tamayo P, Mootha VK, Mukherjee S, Ebert BL, Gillette MA, Paulovich A, Pomeroy SL, Golub TR, Lander ES, Mesirov JP. 2005. Gene set enrichment analysis: a knowledge-based approach for interpreting genome-wide expression profiles. PNAS 102:15545-15550. DOI: https://doi.org/10.1073/pnas.0506580102, PMID: 16199517

Tai AX, Kromer LF. 2014. Corticofugal projections from medial primary somatosensory cortex avoid EphA7expressing neurons in striatum and thalamus. Neuroscience 274:409-418. DOl: https://doi.org/10.1016/j. neuroscience.2014.05.039, PMID: 24909897

Telezhkin V, Schnell C, Yarova P, Yung S, Cope E, Hughes A, Thompson BA, Sanders P, Geater C, Hancock JM, Joy S, Badder L, Connor-Robson N, Comella A, Straccia M, Bombau G, Brown JT, Canals JM, Randall AD, Allen ND, et al. 2016. Forced cell cycle exit and modulation of GABAA, CREB, and GSK3 $\beta$ signaling promote functional maturation of induced pluripotent stem cell-derived neurons. American Journal of Physiology-Cell Physiology 310:C520-C541. DOI: https://doi.org/10.1152/ajpcell.00166.2015, PMID: 26718628

The Gene Ontology Consortium. 2017. Expansion of the gene ontology knowledgebase and resources. Nucleic Acids Research 45:D331-D338. DOI: https://doi.org/10.1093/nar/gkw1108, PMID: 27899567

Tong Y, Chabot JG, Shen SH, O'Dowd BF, George SR, Quirion R. 2000. Ontogenic profile of the expression of the mu opioid receptor gene in the rat telencephalon and diencephalon: an in situ hybridization study. Journal of Chemical Neuroanatomy 18:209-222. DOI: https://doi.org/10.1016/S0891-0618(00)00043-0, PMID: 107 81737

Victor MB, Richner M, Hermanstyne TO, Ransdell JL, Sobieski C, Deng PY, Klyachko VA, Nerbonne JM, Yoo AS 2014. Generation of human striatal neurons by microRNA-dependent direct conversion of fibroblasts. Neuron 84:311-323. DOI: https://doi.org/10.1016/j.neuron.2014.10.016, PMID: 25374357

Voisin J, Farina F, Naphade S, Fontaine M, Tshilenge KT, Galicia Aguirre C, Lopez-Ramirez A, Dancourt J, Ginisty A, Sasidharan Nair S, Lakshika Madushani K, Zhang N, Lejeune FX, Verny M, Campisi J, Ellerby LM, Neri C. 2020. FOXO3 targets are reprogrammed as Huntington's disease neural cells and striatal neurons face senescence with p16 ${ }^{\text {INK4a }}$ increase. Aging Cell 19:e13226. DOI: https://doi.org/10.1111/acel.13226, PMID: 33156570

Wälchli T, Wacker A, Frei K, Regli L, Schwab ME, Hoerstrup SP, Gerhardt H, Engelhardt B. 2015. Wiring the vascular network with neural cues: a CNS perspective. Neuron 87:271-296. DOI: https://doi.org/10.1016/j. neuron.2015.06.038, PMID: 26182414

Wang L, Bluske KK, Dickel LK, Nakagawa Y. 2011a. Basal progenitor cells in the embryonic mouse thalamus their molecular characterization and the role of neurogenins and Pax6. Neural Development 6:35. DOI: https:// doi.org/10.1186/1749-8104-6-35, PMID: 22077982

Wang B, Lufkin T, Rubenstein JL. 2011b. Dlx6 regulates molecular properties of the striatum and central nucleus of the amygdala. The Journal of Comparative Neurology 519:2320-2334. DOI: https://doi.org/10.1002/cne. 22618, PMID: 21452241

Wang H, Matise MP. 2016. Tcf7/2/Tcf4 transcriptional repressor function requires HDAC activity in the developing vertebrate CNS. PLOS ONE 11:e0163267. DOI: https://doi.org/10.1371/journal.pone.0163267، PMID: 27668865

Warde-Farley D, Donaldson SL, Comes O, Zuberi K, Badrawi R, Chao P, Franz M, Grouios C, Kazi F, Lopes CT, Maitland A, Mostafavi S, Montojo J, Shao Q, Wright G, Bader GD, Morris Q. 2010. The GeneMANIA prediction server: biological network integration for gene prioritization and predicting gene function. Nucleic Acids Research 38:W214-W220. DOI: https://doi.org/10.1093/nar/gkq537, PMID: 20576703

Washburn CP, Cooper MA, Zhou R. 2007. Expression of the tyrosine kinase receptor EphA5 and its ligand ephrin-A5 during mouse spinal cord development. Neuroscience Bulletin 23:249-255. DOI: https://doi.org/10. 1007/s12264-007-0037-7, PMID: 17952132

Wei ZZ, Yu SP, Lee JH, Chen D, Taylor TM, Deveau TC, Yu AC, Wei L. 2014. Regulatory role of the JNK-STAT1/3 signaling in neuronal differentiation of cultured mouse embryonic stem cells. Cellular and Molecular Neurobiology 34:881-893. DOI: https://doi.org/10.1007/s10571-014-0067-4, PMID: 24913968 
Wenzl K, Troppan K, Neumeister P, Deutsch AJ. 2015. The nuclear orphan receptor NR4A1 and NR4A3 as tumor suppressors in hematologic neoplasms. Current Drug Targets 16:38-46. DOI: https://doi.org/10.2174/ 1389450115666141120112818, PMID: 25410408

Wichterle H, Lieberam I, Porter JA, Jessell TM. 2002. Directed differentiation of embryonic stem cells into motor neurons. Cell 110:385-397. DOI: https://doi.org/10.1016/S0092-8674(02)00835-8, PMID: 12176325

Wu YE, Pan L, Zuo Y, Li X, Hong W. 2017. Detecting activated cell populations using Single-Cell RNA-Seq. Neuron 96:313-329. DOI: https://doi.org/10.1016/j.neuron.2017.09.026

Xu Z, Liang Q, Song X, Zhang Z, Lindtner S, Li Z, Wen Y, Liu G, Guo T, Qi D, Wang M, Wang C, Li H, You Y, Wang X, Chen B, Feng H, Rubenstein JL, Yang Z. 2018. SP8 and SP9 coordinately promote D2-type medium spiny neuron production by activating Six3 expression. Development 145:dev165456. DOI: https://doi.org/10. 1242/dev.165456, PMID: 29967281

Xu R, Brawner AT, Li S, Liu JJ, Kim H, Xue H, Pang ZP, Kim WY, Hart RP, Liu Y, Jiang P. 2019. OLIG2 drives abnormal neurodevelopmental phenotypes in human iPSC-Based organoid and chimeric mouse models of down syndrome. Cell Stem Cell 24:908-926. DOI: https://doi.org/10.1016/j.stem.2019.04.014, PMID: 31130512

Xu Q, van Heeringen SJ, Frölich S, van der Sande M. 2021. ANANSE: ANalysis Algorithm for Networks Specified by Enhancers. Github. cc7e467. https://github.com/vanheeringen-lab/ANANSE

Ye Y, Barghouth M, Luan C, Kazim A, Zhou Y, Eliasson L, Zhang E, Hansson O, Thevenin T, Renström E. 2020. The TCF7L2-dependent high-voltage activated calcium channel subunit $\alpha 2 \delta-1$ controls calcium signaling in rodent pancreatic beta-cells. Molecular and Cellular Endocrinology 502:110673. DOI: https://doi.org/10.1016/j. mce.2019.110673, PMID: 31805307

Yu G, Wang LG, Han Y, He QY. 2012. clusterProfiler: an R package for comparing biological themes among gene clusters. OMICS: A Journal of Integrative Biology 16:284-287. DOI: https://doi.org/10.1089/omi.2011.0118, PMID: 22455463

Zawadzka M, Rivers LE, Fancy SP, Zhao C, Tripathi R, Jamen F, Young K, Goncharevich A, Pohl H, Rizzi M, Rowitch DH, Kessaris N, Suter U, Richardson WD, Franklin RJ. 2010. CNS-resident glial progenitor/stem cells produce schwann cells as well as oligodendrocytes during repair of CNS demyelination. Cell Stem Cell 6:578590. DOI: https://doi.org/10.1016/j.stem.2010.04.002, PMID: 20569695

Zeisel A, Hochgerner H, Lönnerberg P, Johnsson A, Memic F, van der Zwan J, Häring M, Braun E, Borm LE, La Manno G, Codeluppi S, Furlan A, Lee K, Skene N, Harris KD, Hjerling-Leffler J, Arenas E, Ernfors P, Marklund U, Linnarsson S. 2018. Molecular architecture of the mouse nervous system. Cell 174:999-1014. DOI: https:// doi.org/10.1016/j.cell.2018.06.021, PMID: 30096314

Zeng H, Qin L, Zhao D, Tan X, Manseau EJ, Van Hoang M, Senger DR, Brown LF, Nagy JA, Dvorak HF. 2006. Orphan nuclear receptor TR3/Nur77 regulates VEGF-A-induced angiogenesis through its transcriptional activity. Journal of Experimental Medicine 203:719-729. DOl: https://doi.org/10.1084/jem.20051523, PMID: 16520388

Zhang Y, Liu T, Meyer CA, Eeckhoute J, Johnson DS, Bernstein BE, Nusbaum C, Myers RM, Brown M, Li W, Liu XS. 2008. Model-based analysis of ChIP-Seq (MACS). Genome Biology 9:R137. DOI: https://doi.org/10.1186/ gb-2008-9-9-r137, PMID: 18798982

Zhang N, An MC, Montoro D, Ellerby LM. 2010. Characterization of human Huntington's Disease Cell Model from Induced Pluripotent Stem Cells. PLOS Currents 2:RRN1193. DOI: https://doi.org/10.1371/currents. RRN1193, PMID: 21037797

Zhang Q, Zhang Y, Wang C, Xu Z, Liang Q, An L, Li J, Liu Z, You Y, He M, Mao Y, Chen B, Xiong ZQ, Rubenstein JL, Yang Z. 2016. The zinc finger transcription factor Sp9 is required for the development of striatopallidal projection neurons. Cell Reports 16:1431-1444. DOI: https://doi.org/10.1016/j.celrep.2016.06.090, PMID: 27452460 